$\checkmark$ Research Square

\title{
Micro-Extrusion Process And Microstructure Evolution of Miniature Heat Pipe In 6063 Aluminum Alloy
}

\section{Yongda Liu}

Harbin Institute of Technology

JieXu ( $\nabla$ xjhit@hit.edu.cn )

Harbin Institute of Technology https://orcid.org/0000-0001-5220-3238

Zhengwu Zhang

Harbin Institute of Technology

Gang Liu

Shanghai Institute of Spacecraft Equipment

Debin Shan

Harbin Institute of Technology

Lixin Zhang

Shanghai Institute of Spacecraft Equipment

Bin Guo

Harbin Institute of Technology

\section{Research Article}

Keywords: aluminium alloy, miniature heat pipe, micro-extrusion, porthole die, microstructure

Posted Date: September 9th, 2021

DOl: https://doi.org/10.21203/rs.3.rs-878228/v1

License: (c) (i) This work is licensed under a Creative Commons Attribution 4.0 International License. Read Full License 


\section{Abstract}

Micro-extrusion process of miniature heat pipe with axial micro grooves is particularly difficult due to ultra-large extrusion ratio and complex cross-sectional shape. In this study, the shape control of a miniature heat pipe in 6063 aluminum alloy with boundary dimension of $5 \times 4 \mathrm{~mm}$ has been successfully realized during micro-extrusion. Micro-extrusion process and microstructure evolution of the miniature heat pipe were investigated by the combination of finite element $(\mathrm{FE})$ analysis with experiments. The results show that material flow deformation behavior during micro-extrusion is highly affected by size effect, and lower ram speed is conductive to forming integrity, dimension accuracy and surface quality of the heat pipe profile. The primary mechanism for micro-extrusion failure of micro-grooves is severely more uneven material flow between the micro rib and base region at higher ram speed, which is caused by size effect and results in shear deformation and even fractures of micro rib. Further research shows that, compared to the extrusion using as-cast billets, much coarser grains were obtained after microextrusion using as-extruded billets at an ultra-large extrusion ratio of 205. Besides that, the entirely different texture components after extrusion were obtained instead of the typical $<100>/ / E D$ or $<111>$ //ED fiber texture components. These atypical texture components can be regarded as texture deviating from ideal texture by a certain angle $\left(15^{\circ}\right.$ or $\left.20^{\circ}\right)$ along $\varphi$ axis or $\varphi_{1}$ axis.

\section{Introduction}

Heat pipe is an efficient heat transfer device relying on phase change of the internal working liquid, and its thermal conductivity is hundreds or even thousands of times that of pure copper [1]. Up to now, heat pipe is widely used in electrical and electronic, aerospace, and other fields [2-5]. In recent years, research on lightweight heat pipe has become active $[5,6]$, especially in the aerospace field. Lightweight materials such as aluminum alloy are conducive to cost design of the thermal control systems in satellites. It is reported that Space X's offer for small satellites in sun-synchronous orbits is already US\$1 million per $200 \mathrm{~kg}$ [7]. In addition, miniaturization is also one of the ways to lightweight design, and thus miniature heat pipe in aluminum alloy will have broader application prospects in the heat dissipation of high heat flux density electronic devices in aerospace and other fields.

Axial grooved structure is commonly employed as the capillary wick of aluminum alloy heat pipe for space satellites [8]. The container of this heat pipe is a hollow profile with complex cross-section, and its inner surface is generally designed with an axial micro groove less than $1 \mathrm{~mm}$ in both directions. Consequently, manufacturing of this heat pipe belongs to the category of microforming technology [9]. The material flow deformation behavior in microforming process becomes abnormal due to the existence of size effect usually adverse to plastic forming $[10,11]$ which is also one of the key factors restricting developments of axial grooved heat pipe manufacturing technology.

Extrusion process with a porthole die is particularly appropriate to manufacture hollow profiles [12], and thus extrusion is one of the most used methods to manufacture heat pipe with micro grooves in aluminum alloy [13]. To be precise, it should be called micro-extrusion. The previous research on micro- 
extrusion mainly focuses on the mechanism of size effect and how to overcome the adverse influence of size effect on plastic processing, and thus micro-forward or backward extrusion of micro parts with simple shape are mostly employed to investigate [14-17]. Therefore, to the knowledge of the author, at least 5 satellite heat pipe suppliers in the world could provide solutions for the axial grooved MHPs with diameters from $9 \mathrm{~mm}$ to $25 \mathrm{~mm}$ as early as 2003 [18], but little research on micro-extrusion process of macro parts with micro features such as heat pipe was reported. In addition, even though material microstructure is also highly essential for heat pipe, the known research on micro-extrusion of heat pipe mainly focuses on geometric shape control. Ding et al. [19] presented a porthole die with a reasonable bulging angle of $16^{\circ}$ to manufacture 6063 aluminum alloy double-wing and double-hole heat pipe with $\Omega$ shape groove, which improved the problem of die failure caused by stress concentration of the extrusion die at a large extrusion ratio.

However, it is much more difficult for the micro-extrusion of miniature heat pipe (MHP) with micro grooves in aluminum alloy, and research on manufacturing has not been seen yet. The boundary dimensions of the MHP profile are typically only a few millimeters, and thus ultra-large extrusion ratio on conventional press and very small size of die core are great problems in the extrusion process. Large extrusion ratio means higher extrusion pressures and more inhomogeneous material flow, which are two major causes of extrudate surface or internal defects and die damages [20,21]. Nevertheless, large extrusion ratio also has some advantages such as refining dynamic recrystallization (DRX) grains [22], enhancing mechanical properties [23, 24], and increasing wear resistance [25]. Furthermore, according to reports [26,27], the secondary extrusion process can also improve mechanical properties of materials and form some new texture components. Wu et al. [26] found that, after peak aging of the Mg-RE alloy, the ultimate tensile strength increased from $362 \mathrm{MPa}$ of the single-extruded alloy to $428 \mathrm{MPa}$ of the secondary-extruded alloy as a result of precipitate strengthening. Moreover, an atypical texture component of c-axes aligned along the extrusion direction (ED) was found.

In this current work, based on the above review, micro-extrusion process and microstructure evolution of a $5 \times 4 \mathrm{~mm}$ MHP profile at an ultra-large extrusion ratio of 205 were investigated. The as-extruded solid round bar in 6063-T6 aluminum alloy was selected as extrusion billets. with the help of HyperXtrude ${ }^{\circledR}$ (HX) software, the steady state extrusion process of the MHP profile was simulated by FE analysis. The effect of ram speed on forming integrity of micro grooves, dimension accuracy and surface morphology of the MHP profile were experimentally investigated, and then the micro-extrusion forming mechanism of micro grooves was revealed. Further, microstructure evolution in the MHP profile was studied using metallographic test and electron backscatter diffraction (EBSD) technique. The research results in this paper provide a certain reference and basis for the shape and properties regulation of miniature hollow profiles like the MHP profile manufactured by micro-extrusion process.

\section{Experimental Methods}

\subsection{Die design and manufacturing}


Reasonable die design is the most critical factor to ensure successful micro-extrusion. The MHP profile investigated in this work is shown in Fig. 1. Geometrical characteristics of the MHP profile were analyzed before die design. It is a fully symmetrical structure along the $X$ and $Y$ axis. The most critical dimension of the profile is the narrow slit width $(0.35 \mathrm{~mm})$ of the micro trapezoidal groove. Smaller narrow slit width plays a positive role in heat transfer limit of the heat pipe from the perspective of heat and mass transfer [28], but which also makes great trouble for the design of extrusion die. The minimum inner diameter of the profile corresponding to the maximum outer diameter of the die core is $1.68 \mathrm{~mm}$. The minimum and maximum wall thickness of the profile are respectively $0.37 \mathrm{~mm}$ and $1.68 \mathrm{~mm}$, and consequently the maximum difference value of wall thickness is $78 \%$.

Forward extrusion with a porthole die was employed to manufacture the MHP profile, as shown in Fig. 2. According to geometrical characteristics of the MHP profile, the porthole die follows four design principles below. Firstly, the porthole, welding chamber and bearing were designed to be symmetrical along the $X$ and $Y$ axis. Secondly, in consideration of die strength and abrasion resistance during microextrusion, $\mathrm{H} 13$ steel after quenching and nitriding was used to fabricate the porthole die. Moreover, the length of the die core should be smaller as far as possible, and the transition region between micro grooves and other sections of the die core was designed as a slope structure for enough strength. Thirdly, the number of longitudinal welds in the MHP profile was reduced to 2 by means of two independent welding chamber designs to improve mechanical properties of the profile. Finally, main dimensions of the porthole die such as length of bearing, welding chamber and porthole, as well as porthole outer radius, are shown in Fig. 3.

The manufactured porthole die used to produce the MHP profile is shown in Fig. 4. Fabrication of the die core is extremely difficult because of small size, micro trapezoidal groove and high dimensional accuracy requirements of the die core, and thus traditional CNC machine tools are difficult to meet these processing demands. Therefore, micro electrical discharge machining (EDM) was employed to manufacture the die core. Results show that geometric dimensions of the die core processed by EDM are within design tolerance, and excellent surface quality is obtained. As shown in Fig. 4(b), the surface of the die core exhibits a stacked layered mushroom-like morphology.

\subsection{Experimental procedure}

The commercial as-extruded 6063-T6 aluminum alloy solid round bar with boundary dimensions of $\varnothing 85 \times 200 \mathrm{~mm}$ was used as extrusion billets, and the analyzed chemical compositions are given in Table 1. The micro-extrusion experiment with an extrusion ratio of 205 was performed on a $6.3 \mathrm{MN} \mathrm{Al} \mathrm{\&} \mathrm{Mg}$ profile extrusion line. Preheating temperature and ram speed are the main process parameters in hot extrusion. The preheating temperatures of billet, die, and container are respectively $480{ }^{\circ} \mathrm{C}, 460{ }^{\circ} \mathrm{C}$ and $450{ }^{\circ} \mathrm{C}$, and the ram speeds are respectively $0.7 \mathrm{~mm} / \mathrm{s}$ and $1.4 \mathrm{~mm} / \mathrm{s}$. Due to higher strength of asextruded billets, preheating temperatures were set as a little higher than that of as-cast billets in conventional extrusion. Billets were preheated to the target temperature after 220 min in a box-type resistance furnace, and then extrusion experiments were carried out. The extruded profiles at high temperature were cooled naturally and treated with natural aging. 
Table 1

Chemical compositions of 6063 aluminum alloy.

\begin{tabular}{|ccccccccccc|}
\hline Si & Fe & Cu & Mn & Mg & Zn & Cr & Ti & Ni & Sn & Al \\
\hline 0.60 & 0.25 & 0.16 & 0.28 & 0.80 & 0.10 & 0.01 & 0.015 & 0.05 & 0.05 & Bal. \\
\hline
\end{tabular}

In this work, the research focuses on the initial stage of steady-state extrusion when the MHP profile is mainly extruded from materials at the center of the billets. As shown in Fig. 5, the profile at the initial stage of steady-state extrusion was divided into four sections. The ram speed of the first three sections (I$1, I-2, I-3)$ is nominally $1.4 \mathrm{~mm} / \mathrm{s}$, but in consideration of the ram acceleration time, it gradually ranges from 0 to $1.4 \mathrm{~mm} / \mathrm{s}$ in practice. The fourth section (II) profile was extruded with a ram speed of $0.7 \mathrm{~mm} / \mathrm{s}$.

Test samples were taken from the above four sections. Forming integrity, dimension accuracy, surface morphology and microstructure of the MHP profile were subsequently measured. Specifically, forming integrity and dimension accuracy were obtained by a VMS-2515F video measuring system. Surface morphology was observed using a FEI Quanta 200FEG scanning electron microscope (SEM), and roughness was measured by an Olympus OLS-3000 laser confocal microscope. Furthermore, to obtain the metallographic structure, the profile cross-section was electropolished to a mirror-like surface with a voltage of $25 \mathrm{~V}$ in a mixed solution containing $10 \mathrm{vol} \%$ perchloric acid and $90 \mathrm{vol} \%$ alcohol, and then anode coating was carried out with a voltage of $20 \mathrm{~V}$ which was conducted for $150 \mathrm{~s}$ in a mixed solution containing $5 \mathrm{ml}$ fluoroboric acid and $200 \mathrm{ml}$ deionized water. Subsequently, metallographic observation was conducted on a Zeiss Axio Imager A2m optical microscope (OM). In order to further investigate the characteristics of grains and micro-texture, EBSD tests for zone 3 of the as-extruded billets and the MHP profile extruded at a ram speed of $0.7 \mathrm{~mm} / \mathrm{s}$ were performed on the above SEM equipped with an Oxford EBSD accessory, and then EBSD data were analyzed by a program TSL OIM.

\section{Results And Discussion}

\subsection{FE analysis of micro-extrusion}

The steady state micro-extrusion process of the MHP profile was simulated by means of HX software based on arbitrary Lagrange-Eulerian (ALE) algorithm, and the distributions of velocity, temperature, and strain were obtained. HX was selected since specifically used in the extrusion process and widely verified in previous studies [e.g., [11], [29]].

The following pretreatment was conducted before FE analysis. The one-half axisymmetric material flow domain was created and then discretized by meshing, as shown in Fig. 6. The material flow domain includes billet, porthole, welding chamber, bearing and profile. Triangular prism element is adopted in the bearing and profile, and the rest is tetrahedral element. The material constitutive model of 6063 aluminum alloy in the material library of HX software was selected, and ram speed and preheating 
temperature parameters were defined according to the above experimental procedure. In addition, extrusion simulations with the ram speeds of $2.1 \mathrm{~mm} / \mathrm{s}$ and $2.8 \mathrm{~mm} / \mathrm{s}$ were also carried out to investigate the effect of ram speed on micro-extrusion process. In general, the friction condition of the bearing is set as sliding friction $[11,29]$. However, the ultra-large extrusion ratio of the MHP profile results in higher contact stress, and the phenomenon of 6063 aluminum alloy sticking to die is more severe due to the complex shape of the profile. Therefore, the friction condition between bearing and materials was set as viscoplastic friction with a friction factor of 0.3 , and the rest was set as sticky friction. Heat transfer coefficient between materials and porthole die was set as $3000 \mathrm{~W} / \mathrm{m}^{2 .{ }^{\circ}} \mathrm{C}$.

Figure 7 (a) shows the shape of the head profile, and the shape of the head profile obtained by FE analysis is in good agreement with the subsequent experiment results. As shown in Fig. 7(a), the material flow in the micro rib region of the profile is apparently lagging compared to the base region. Figure 7 (b) shows that the profile exit velocity (PEV) at the micro rib region is considerably lower than that of the base region. Obviously, size effect has a significant negative influence on the material flow behavior during micro-extrusion, which leads to the serious hysteresis of material flow at the micro rib region. Specifically, this inhomogeneity of material flow between micro rib and base region is mainly caused by the difference of difficulty level for the material flow. Since the geometric dimension of the micro-rib is even less than $0.5 \mathrm{~mm}$, and thereby the influence degree of friction force on material flow at micro rib region is much greater than that at the base region, and then the material flow here is more difficult. As a result, the PEV at micro rib region is considerably slower, and then the micro rib region of the head profile shows a severe material flow lag phenomenon macroscopically. Generally, the inhomogeneity of material flow during extrusion can be improved by the bearing optimization of extrusion die, but the optimization space for micro-extrusion of micro parts like the MHP profile is very limited. This is because the difference between the minimum feature size and the maximum size of the heat pipe is too enormous.

In addition, as shown in Fig. 6 and Fig. 7, the distribution of temperature and strain is not completely asymmetrical due to the incomplete symmetrical design of the welding chamber, and the temperature is a little higher at the center of the MHP profile due to the more difficult heat dissipation here. It can also be found that the ram speed has a significant effect on the temperature of the profile, but the effect on the strain is not significant. On the one hand, as the ram speed increases from $0.7 \mathrm{~mm} / \mathrm{s}$ to $1.4 \mathrm{~mm} / \mathrm{s}$, the maximum temperature of the MHP profile increases by $24.2^{\circ} \mathrm{C}$, and the temperature difference between the center and the edge of the MHP profile increases from $7.1^{\circ} \mathrm{C}$ to $11.7^{\circ} \mathrm{C}$ at a maximum. On the other hand, the deformation at the micro rib region, the welding region and the region contacting with the bearing is more severe, and thus the strain value at the micro rib locating on the welding region is highest.

\subsection{Effect of ram speed on forming quality}

The forming quality of the MHP profile manufactured by micro-extrusion investigated in this work involves forming integrity, dimension accuracy and surface roughness. The experimental results show that ram speed has a great influence on forming quality of micro-extrusion. 
Ram speed can significantly affect forming integrity and dimension accuracy of the MHP profile, as shown in Fig. 8, Fig. 9. With an ultra-large extrusion ratio of 205, lower ram speed is beneficial to microextrusion forming and dimension accuracy of micro grooves on the inner wall of the MHP profile. The forming integrity results of micro grooves are shown in Fig. 8. Obviously, the number of extruded micro grooves decreases sharply with the increase of ram speed. Although all the micro grooves of both

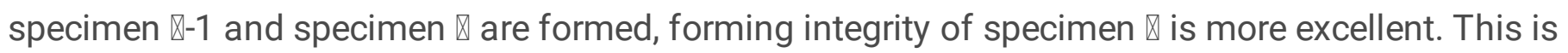

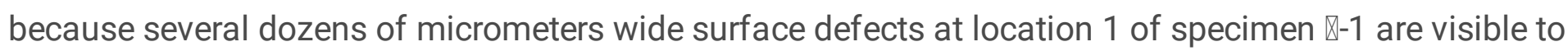
the naked eye, and the round corner at its location 2 is not filled enough as well. Moreover, interestingly,

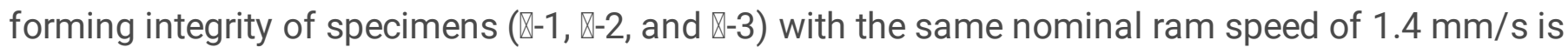
extremely different. It can be concluded that, at the onset stage of ram acceleration, ram speed is low and beneficial to the microforming of micro grooves. Therefore, the number of extruded micro grooves dropped sharply from 8 to 0 as ram speed accelerated to $1.4 \mathrm{~mm} / \mathrm{s}$. Meanwhile, the key geometric dimension (i.e., narrow slit width of micro trapezoidal grooves) of the above specimens was measured, as shown in Fig. 9. Only dimension accuracy of specimen $\triangle$ meets the design requirement of narrow slit

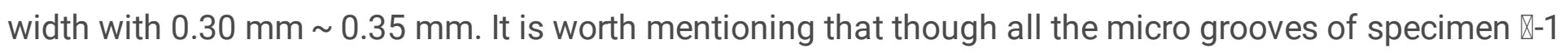
were extruded successfully, these dimensions are partly out of tolerance. It follows that the aluminum alloy at lower ram speeds is filled more fully when flowing in micro grooves of the porthole die, which results in good geometric shapes and dimension accuracy.

Ram speed also has a great effect on surface morphology of the MHP profile. The typical surface streaks formed in micro-extrusion can be observed on both internal and external surfaces of the MHP profile, as shown in Fig. 10, Fig. 12. As ram speed increases, surface quality of the MHP profile deteriorates significantly with the appearance of micro-voids, microcracks, and even fractures of micro rib. Figure 10 shows two distinct surface morphologies on the micro ribs of the MHP profile extruded at different ram speeds. On the one hand, MHP profiles with micro grooves completely formed shown in Fig. 10 (a), (d) exhibit very similar surface streaks morphology when observed by low magnification SEM. However, the high magnification SEM image shows that the surface of specimen $1-1$ is worse than specimen $\nabla$ because of the microcrack initiation and propagation along the second-phase particles. On the other hand, for MHP profiles with only partial micro grooves extruded, a river-like structure appeared after micro ribs were torn from the internal wall of the profile, as shown in Fig. 10 (b), (c). As ram speed rose to $1.4 \mathrm{~mm} / \mathrm{s}$, the wave-like structure even rolled up. High magnification SEM images show that the size of micro-voids and microcracks on the wave-like structure become larger with the increase of ram speed. For the causes of microcracks, according to the previous research [30], the temperature increase at higher ram speed can result in the hot cracking limit of 6063 aluminium alloy being exceeded, and the incipient melting of second-phase particles is usually the cause of hot cracking. Further, the basic reason for formation of the river-like structure is extremely uneven material flow between micro rib and base region during microextrusion, and the detailed explanations combining FE analysis and experiment results will be given in the following section.

In order to investigate the effect of ram speed on surface roughness of the profile, the external surface roughness of the MHP profile was measured. Figure 11 shows that the roughness Ra value of external 
surfaces extruded at a lower ram speed of $0.7 \mathrm{~mm} / \mathrm{s}$ is much smaller, which is caused by local underfilling of the extrudate at higher ram speed, as shown position 1 in Fig. 8. Moreover, the data consistency of roughness Ra value at a lower true ram speed is also better, such as specimen $\nabla-1$ and specimen $\nabla$.

To sum up, a better ram velocity of $0.7 \mathrm{~mm} / \mathrm{s}$ was finally selected in this work to guarantee forming integrity and dimension accuracy of micro grooves and surface quality of the profile. The MHP profile was successfully extruded in bulk with the above process parameters. Figure 12 shows the appearance and surface morphology of the manufactured MHP profile. The excellent dimensional accuracy and surface quality are satisfactory, which has reached the standards for aerospace applications, and the control of "shape" of the MHP profile has been realized.

\subsection{Forming mechanism of micro grooves}

It can be found from the above research results that the micro-extrusion of the MHP profile can easily fail due to size effect. Therefore, the deep understanding of the forming mechanism of micro-grooves during the micro-extrusion process has important guiding significance for the micro-extrusion die and process optimization of similar parts like the MHP profile.

In order to quantify the inhomogeneity of material flow at the exit of the MHP profile, referring to the previous studies $[19,21]$, the standard deviation of velocity (SDV) value for the PEV is adopted, and expressed as follows:

$S D V=\sqrt{\frac{\sum_{i=1}^{n}\left(v_{i}-\bar{v}\right)^{2}}{n}}$

where, $v_{i}$ is the velocity of the center nodal at the selected region $i, \bar{v}$ is the average velocity of all the selected regions, and $\mathrm{n}$ is the number of selected regions. Larger SDV value represents more uneven material flow. Since the MHP profile is fully axisymmetric along the $X$ and $Y$ direction, a quarter of the profile cross-section was chosen to calculate SDV value. Figure 13(a) shows the partition diagram of the profile cross-section and the variation of SDV value with ram speed. The linear fitting result shows Rsquare value is 0.9997 , which is very close to 1 , and thus an extremely strong positive linear correlation between ram speed and SDV value exists. In other words, as ram speed increases, the inhomogeneity of material flow also rises explosively on account of the ultra-large extrusion ratio during micro-extrusion.

Based on the simulation and experiment results, the micro-extrusion forming mechanism of microgrooves was analyzed. The primary reason for the failure of micro-extrusion is the uneven material flow, which brings about a huge difference in PEV between micro rib and base region. It is this difference that results in material flow of the micro rib region seriously lagging that of the base region. According to SDV value results, when ram speed is enhanced, the uneven flow will linearly and dramatically increase. According to Fig. 13(b), the relative velocity difference (RVD) between micro rib and base region is expressed as follows: 
$R V D=\frac{\left(v_{b}-v_{m}\right)}{v_{b}} \times 100 \%$

where, $v_{b}$ is the PEV of the base region, and $v_{m}$ is the PEV of the micro rib region. Due to the difference of material flow velocity at two regions, the shear deformation along ED will occur between two regions after reaching yield strength of the material during extrusion. When the maximum value of RVD exceeds a certain threshold, micro rib will be torn from the inner wall of the MHP profile to form the river-like structure shown in Fig. 10, and thus micro grooves fail to be extruded.

\subsection{Microstructure evolution after micro-extrusion}

\subsubsection{Microstructure evolution at different ram speed}

Surprisingly, with an ultra-large extrusion ratio, the grains obtained by porthole die extrusion using asextruded billets are obviously coarser, which is contrary to previous reports [22]. Generally, coarse grains of aluminum alloy as-cast billets will be refined after hot extrusion [33].Ram speed during micro-extrusion also plays a great role in microstructure evolution of 6063 aluminum alloy, and higher ram speed can inhibit excessive grain growth to a certain extent.

First of all, the metallographic structure of the longitudinal section of the as-extruded billets sampled at different positions were analyzed. As shown in Fig. 14, significant differences in morphology and size of the grains were observed. Zone 1 is mainly composed of fine recrystallized grains, but the surface layer of the billets shows a typical coarse grain ring [31] with a thickness of about $200 \mu \mathrm{m}$. Zone 2 is mainly composed of typical fibrous deformed grains elongated in the extrusion process and a few equiaxed crystals formed after recrystallization. The grain morphologies of zone 3 and zone 2 are very similar, while the grains at zone 3 are bigger. Subsequently, metallographic microstructure of the as-extruded billets after preheating was observed, as shown in Fig. 14 (e) (f), the morphology of grains has not changed significantly. These above results can be attributed to high stacking fault energy of aluminum alloy. Since aluminum alloys are generally prone to dislocation climb and cross slip during hightemperature deformation, sufficient dynamic recovery occurs, resulting in insufficient deformation storage energy for DRX [32]. In consequence, only the most severely deformed outer layer of the as-extruded billets was completely recrystallized.

Subsequently, the metallographic structure at the whole cross-section of the MHP profile was obtained by means of image stitching technology. Figure 15 shows that completely DRX occurred after the asextruded billets underwent severe plastic deformation in the high-temperature closed porthole die. It can be found that higher ram speed can inhibit excessive grain growth, but which is contrary to the control strategy of "shape" of the MHP profile. Specifically, the grain size of specimen I-2 and specimen I-3 obtained at a higher nominal ram speed of $1.4 \mathrm{~mm} / \mathrm{s}$ is smaller. FE analysis results in Fig. 7 (c) (d) (e) (f) show temperature and strain distributions of the profile cross-section are nearly identical at different ram speeds, and the biggest difference is that the theoretical maximum PEV of $423.2 \mathrm{~mm} / \mathrm{s}$ for specimen I-3

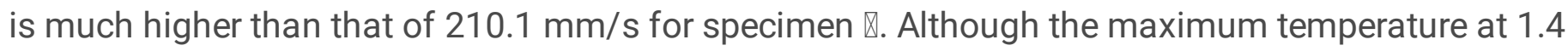
$\mathrm{mm} / \mathrm{s}$ is $24.2^{\circ} \mathrm{C}$ higher than that at $0.7 \mathrm{~mm} / \mathrm{s}$, it is obvious that higher PEV can significantly reduce the 
dwell time of materials in the deformation zone of the porthole die, and lower the degree of excessive grain growth.

In addition, it is worth noting that there is an unexpected significant difference in grain size at the axisymmetric locations on the profile cross-section. It can be found from Fig. 6 that the fundamental

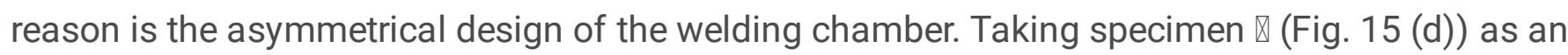
example, the grain size at position $A$ is bigger than that at position $B$. Although the temperature and PEV at position $A$ and position $B$ are very nearly the same, Fig. 7 (e) reveals that the strain at position $A$ is greater. Chen et.al found that the volume fraction of DRX is usually in accordance with the distribution of strain [33], and thus the high strain at position A is susceptible to promoting the occurrence of DRX and the subsequent grain growth.

\subsubsection{Grain characteristics of MHP profile}

Based on the above metallographic results, the grain size after the micro-extrusion using as-extruded billets is very abnormal. In order to further investigate the grain characteristics of the MHP profile, EBSD analysis for the MHP profile extruded at a better ram speed of $0.7 \mathrm{~mm} / \mathrm{s}$ was carried out to obtain the grain characteristics such as morphology, size and misorientation angle $\theta$.

The grain of 6063 aluminium alloy was coarsen after micro-extrusion, and Fig. 16 (e) show that the average grain size of the as-extruded billets after micro-extrusion increased sharply from $43.7 \mu \mathrm{m}$ to a maximum of $159 \mu \mathrm{m}$. The abnormal phenomenon occurs due to the history of deformation imposed. In other words, deformation storage energy of the as-extruded billets is higher than that of as-cast billets, coupled with higher preheating temperature in the micro-extrusion process, and thus DRX and grain growth are prone to occur. It can be proved by the change in proportion of low angle grain boundaries (LAGBs) $\left(2^{\circ} \leq \theta<15^{\circ}\right)$ before and after micro-extrusion. As shown in Fig. 16 (f), the LAGBs in zone 3 of

the extruded billets accounts for more than $60 \%$, while the highest proportion of LAGBs in the MHP profile is only $10.3 \%$. After micro-extrusion, the MHP profile in 6063 aluminum alloy is mainly composed of high angle grain boundaries (HAGBs), and the average misorientation angle has risen from $20.4^{\circ}$ to more than $35.0^{\circ}$.

The distribution of grain size at the MHP profile cross-section is also different. As shown in Fig. 16(e), the average grain size of micro rib region (zone a) is at a maximum of $35.6 \mu \mathrm{m}$ smaller than base region (zone b \& zone c), but the excessive grain growth at zone a and zone b is much severe than that at zone c. The uneven distribution of grain size, which is strongly related to the uneven strain distribution at the profile cross-section. Obviously shown in Fig. 7, the strain distribution at zone $\mathrm{c}$ is most uniform, and the temperatures of these three regions are almost the same except for the strain. The smaller average grain size at micro rib region can be mainly attributed to the poor statistics under the condition of the smaller area and bigger grains, hence several small grains on the edge of the micro rib can affect the result of average grain size. 
Furthermore, the region near longitudinal welds was investigated. As seen in Fig. 17, no obvious welds can be observed near the welding region of the profile, indicating that welding quality is very excellent to a certain extent. According to $\mathrm{K}$ criterion [34] predicting welds quality, the integral value of the ratio of the welding pressure with the effective stress of the material to the welding path exceeds a certain value, and then materials are well welded. That is, high pressure in the welding chamber is conducive to the solidstate welding of welds. Obviously, the pressure in the welding chamber of porthole dies at an ultra-large extrusion ratio of 205 is very high, and thus excellent welding quality of the profile was obtained. Interestingly, many grain boundaries parallel to the ED can be observed near longitudinal welds, which is caused by two strands of metal materials from different portholes squeezing against each other under the constraints of the porthole die during extrusion.

\subsubsection{Micro-texture analysis}

Unexpectedly, the micro-texture of 6063 aluminum alloy after micro-extrusion using as-extruded billets is also entirely distinct. In the ordinary way, aluminum alloy after hot extrusion with as-cast billets exhibits a strong fiber texture component such as $<100>/ /$ ED or $<111>/ /$ ED [35], such as the extruded billets in this article (Fig. 16(a), Fig. 18 (a)). Besides that, Kaneko et al. [36] found that the increase in extrusion ratio can enhance $<100>$ texture component and weaken $<111>$ texture component in the extruded Al$\mathrm{Mg}$-Si-Cu alloy rods. However, no typical fiber texture components were observed in 6063 aluminum alloy after micro-extrusion using as-extruded billets, as shown in Fig. 18.

In order to comprehensively investigate the micro-texture after micro-extrusion with as-extruded billets, the ODF sections of texture components in 6063 aluminum alloy after micro-extrusion, as well as FCC alloy, were shown in Fig. 19. Overall, texture components in the region of micro rib and bases are significantly different. What needs to be pointed out is that the deviation of less than $10^{\circ}$ from ideal texture was considered as near the ideal texture in this article. The detailed analysis results of the micro-texture after micro-extrusion are as follows.

Firstly, it can be seen from Table 2 that the micro rib region (zone a) mainly exhibits strong Near Brass/P and Near Cube/R-Goss texture components, followed by significantly weaker Cube/R-Goss texture component. Interestingly, near Brass/P and near Cube/R-Goss texture components deviate from their own corresponding ideal texture component by $10^{\circ}$ along the $\varphi$ axis and $\varphi_{1}$ axis respectively. Secondly, the base region (zone $b$ ) mainly presents a strong atypical texture component deviating from Cube/R-Cube texture component by $20^{\circ}$ along $\varphi$ axis and Cube/R-Goss, followed by Near Cube/R-Goss texture component and the atypical texture component deviating from Cube texture component by $20^{\circ}$ along $\varphi$ axis. And the atypical texture component deviating from Goss/Brass texture component by $20^{\circ}$ along $\varphi$ axis is the weakest. Finally, the base region (zone c) mainly exhibits Cube/R-Cube, Near Cube/R-Cube texture component and an atypical texture component deviating from $\mathrm{E}$ texture component by $15^{\circ}$ along the $\varphi$ axis. 
Table 2

Texture components in 6063 aluminum alloy after micro-extrusion.

\begin{tabular}{|c|c|c|c|c|}
\hline Location & Texture components & Euler angles & Miller Indices & Intensity \\
\hline \multirow[t]{3}{*}{ zone a } & Near Brass/P & $35^{\circ} 80^{\circ} 45^{\circ}$ & $(4-4$ 1) [11-14 12] & 34.9 \\
\hline & Near Cube/R-Goss & $80^{\circ} 65^{\circ} 0^{\circ}$ & 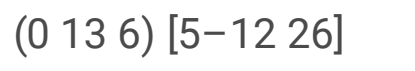 & 21.9 \\
\hline & Cube/R-Goss & $90^{\circ} 35^{\circ} 0^{\circ}$ & (0 7 10) [0-10 7] & 18.0 \\
\hline \multirow[t]{5}{*}{ zone b } & Atypical & $65^{\circ} 20^{\circ} 0^{\circ}$ & (0 4 11) [11-22 8] & 19.8 \\
\hline & Cube/R-Goss & $90^{\circ} 30^{\circ} 0^{\circ}$ & (0 11 19) [0-19 11] & 15.2 \\
\hline & Near Cube/R-Goss & $85^{\circ} 75^{\circ} 0^{\circ}$ & 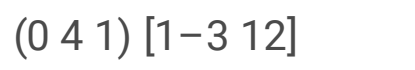 & 10.1 \\
\hline & Atypical & $45^{\circ} 20^{\circ} 45^{\circ}$ & (7 7 27) [1-28 7] & 11.3 \\
\hline & Atypical & $20^{\circ} 65^{\circ} 0^{\circ}$ & $\left(\begin{array}{lll}0 & 2 & 1\end{array}\right)\left[\begin{array}{ll}25 & - \\
-4 & 8\end{array}\right]$ & 8.2 \\
\hline \multirow[t]{6}{*}{ zone c } & Cube/R-Cube & $60^{\circ} 0^{\circ} 45^{\circ}$ & $\left(\begin{array}{lll}0 & 0 & 1\end{array}\right)\left[\begin{array}{lll}-4 & -15 & 0\end{array}\right]$ & 10.5 \\
\hline & & $20^{\circ} 0^{\circ} 0^{\circ}$ & $\left(\begin{array}{lll}0 & 0 & 1\end{array}\right)\left[\begin{array}{ll}11 & -4 \\
-1\end{array}\right]$ & 9.9 \\
\hline & & $20^{\circ} 90^{\circ} 0^{\circ}$ & $\left(\begin{array}{lll}0 & 1 & 0\end{array}\right)\left[\begin{array}{lll}11 & 0 & 4\end{array}\right]$ & 9.9 \\
\hline & Near Cube/R-Cube & $55^{\circ} 10^{\circ} 45^{\circ}$ & $\left(\begin{array}{lll}1 & 1 & 7\end{array}\right)\left[\begin{array}{lll}-1 & -6 & 1\end{array}\right]$ & 9.7 \\
\hline & Atypical & $55^{\circ} 40^{\circ} 45^{\circ}$ & (13 13 22) $\left[\begin{array}{lll}-1 & -21 & 13\end{array}\right]$ & 9.0 \\
\hline & Near Cube/R-Cube & $70^{\circ} 80^{\circ} 0^{\circ}$ & $\left(\begin{array}{lll}0 & 6 & 1\end{array}\right)\left[\begin{array}{lll}2 & -1 & 6\end{array}\right]$ & 6.2 \\
\hline
\end{tabular}

The micro-extrusion process in this paper has a more complicated deformation history due to the employment of as-extruded billets, which is the main cause for the formation of abnormal micro-texture. For the micro-extrusion of as-extruded billets possessing the texture components of $<111>$ and $<100>$ //ED, it actually belongs to secondary extrusion. Plastic deformation promotes the transformation of grain orientation, and thus the atypical texture components form after micro-extrusion. It can be found that the above atypical texture components can be regarded as texture deviating from ideal texture by a certain angle $\left(15^{\circ}\right.$ or $\left.20^{\circ}\right)$ along $\varphi$ axis or $\varphi_{1}$ axis. In addition, the difference in texture components at the micro rib and base region might be strongly related to the difference of material flow deformation on account of size effect. The detailed texture transformation process deserves to be focused on in the future.

\section{Conclusions}

Micro-extrusion process and microstructure evolution of a $5 \times 4 \mathrm{~mm}$ MHP profile at an ultra-large extrusion ratio of 205 were investigated. It must be mentioned that as-extruded solid round bar in 6063 aluminum alloy was selected as extrusion billets. The main conclusions are as follows: 
(1) The effect of ram speed on the forming quality of micro-extrusion for the miniature complicated hollow profile like MHP is highly significant, and lower ram speed is conductive to micro-extrusion forming of micro-grooves, dimension accuracy and surface quality. With the ram speed increasing, surface quality deteriorates significantly with the appearance of micro-voids, microcracks and even fractures.

(2) The primary mechanism for the failure of micro-extrusion forming of micro-grooves is the uneven material flow caused by the size effect, and thereby the material flow at micro rib region seriously lags. This inhomogeneity linearly and explosively increases with ram speed enhancing, and thus shear deformation along ED will occur between micro rib and base region after reaching yield strength of the material. When RVD value exceeds a certain threshold, micro ribs will be torn, and thus micro grooves fail to be extruded.

(3) Grains and texture components after micro-extrusion using as-extruded billets in 6063 aluminium alloy are very abnormal, and the difference in texture components at the micro rib and base region is evident. On the one hand, grains in the MHP profile are greatly coarse instead of grain refinement at an ultra-large extrusion ratio, which can be inhibited by higher ram speed to a certain extent. On the other hand, no typical fiber texture components such as $<100>/ / E D$ or $<111>/ / E D$ were found, to be replaced by these texture components such as near Brass/P, (near) Cube/R-Goss, (near) Cube/R-Cube, and some atypical texture components. These atypical texture components can be regarded as texture deviating from ideal texture by a certain angle $\left(15^{\circ}\right.$ or $\left.20^{\circ}\right)$ along $\varphi$ axis or $\varphi_{1}$ axis.

\section{Declarations}

\section{Funding:}

This work was supported by National Natural Science Foundation of China (Grant No. 51635005).

\section{Author information}

\section{Affiliations}

Key Laboratory of Micro-systems and Micro-structures Manufacturing of Ministry of Education, Harbin Institute of Technology, Harbin, 150080, China

Yongda Liu, Jie Xu, Zhengwu Zhang, Debin Shan \& Bin Guo

School of Materials Science and Engineering, Harbin Institute of Technology, Harbin, 150001, China

Yongda Liu, Jie Xu, Zhengwu Zhang, Debin Shan \& Bin Guo

\section{Shanghai Institute of Spacecraft Equipment, Shanghai, 200240, China}




\section{Authors' contributions}

Yongda Liu wrote the manuscript and contributed to the conception of the study.

Zhengwu Zhang designed and performed the simulation and experiment.

Jie Xu and Bin Guo contributed greatly to analysis and manuscript preparation.

Gang Liu and Lixin Zhang helped perform the analysis with constructive discussions.

Debin Shan provided technical guidance.

All authors discussed the results and significantly contributed to the final manuscript.

Corresponding author

Correspondence to Jie Xu or Bin Guo.

\section{Availability of data and material}

The datasets used or analyzed during this study are available from the corresponding author on reasonable request.

Code availability

Not applicable.

Ethics declarations

\section{Ethics approval}

Not applicable.

\section{Consent to participate}

Not applicable.

\section{Consent for publication}

Not applicable.

\section{Competing interests}

The authors declare no competing interests.

\section{Acknowledgments}

This work was supported by National Natural Science Foundation of China (Grant No. 51635005). 


\section{References}

1. Cotter TP (1965) Theory of Heat Pipes. Los Alamos Scientific Lab, Los Alamos. https://doi.org/10.2172/4619147.

2. Vasiliev LL (2008) Micro and miniature heat pipes - Electronic component coolers. Appl Therm Eng 28 (4):266-273. https://doi.org/10.1016/j.applthermaleng.2006.02.023.

3. Hoa C, Demolder B, Alexandre A (2003) Roadmap for developing heat pipes for ALCATEL SPACE's satellites. Appl Therm Eng 23 (9):1099-1108. https://doi.org/10.1016/S1359-4311(03)00039-5.

4. Seshan S, Vijayalakshmi D (1986) Heat pipes - concepts, materials and applications. Energy Convers Manag 26(1):1-9. https://doi.org/10.1016/0196-8904(86)90025-7.

5. Yang X, Yan Y, Mullen D (2012) Recent developments of lightweight, high performance heat pipes. Appl Therm Eng 33-34:1-14. https://doi.org/10.1016/j.applthermaleng.2011.09.006.

6. Narendra Babu N, Kamath HC (2015) Materials used in Heat Pipe. Mater Today Proc 2 (4-5):14691478. https://doi.org/10.1016/j.matpr.2015.07.072.

7. Jeff F (2019) Space News. SpaceX revamps smallest rideshare program. https://spacenews.com/spacex-revamps-smallsat-rideshare-program/. Accessed 29 August 2019.

8. Sundén B, Fu J (2017) Heat Transfer in Aerospace Applications. Academic Press, Oxford.

9. Geiger M, Kleiner M, Eckstein R, Tiesler N, Engel U (2001) Microforming. Cirp Ann-Manuf Techn 50(2):445-462. https://doi.org/Doi 10.1016/S0007-8506(07)62991-6.

10. Xu J, Zhu XC, Shan DB, Guo B, Langdon TG (2015) Effect of grain size and specimen dimensions on micro-forming of high purity aluminum. Mat Sci Eng a-Struct 646:207-217. https://doi.org/10.1016/j.msea.2015.08.060.

11. Fu MW, Wang JL (2021) Size effects in multi-scale materials processing and manufacturing. Int $\mathrm{J}$ Mach Tool Manu 167: 103755. https://doi.org/10.1016/j.ijmachtools.2021.103755

12. Yu J, Zhao G, Cui W, Chen L, Chen X (2019) Evaluating the welding quality of longitudinal welds in a hollow profile manufactured by porthole die extrusion: Experiments and simulation. J Manuf Process 38:502-515. https://doi.org/10.1016/j.jmapro.2019.01.044.

13. Ömür C, Uygur AB, Horuz İ, Işık HG, Ayan S, Konar M (2018) Incorporation of manufacturing constraints into an algorithm for the determination of maximum heat transport capacity of extruded axially grooved heat pipes. Int J Therm Sci 123:181-190. https://doi.org/10.1016/j.ijthermalsci.2017.09.016.

14. Chan WL, Fu MW, Yang B (2011) Study of size effect in micro-extrusion process of pure copper. Mater Design 32 (7):3772-3782. https://doi.org/10.1016/j.matdes.2011.03.045.

15. Parasiz SA, Kinsey B, Krishnan N, Cao J, Li M (2007) Investigation of deformation size effects during microextrusion. J Manuf Sci E-T Asme 129 (4):690-697. https://doi.org/10.1115/1.2738107.

16. Krishnan N, Cao J, Dohda K (2007) Study of the size effects on friction conditions in microextrusion Part I: microextrusion experiments and analysis. J Manuf Sci E-T Asme 129 (4):669-676. https://doi.org/10.1115/1.2386207. 
17. Mori LF, Krishnan N, Cao J, Espinosa HD (2007) Study of the size effects and friction conditions in microextrusion - Part II: Size effect in dynamic friction for brass-steel pairs. J Manuf Sci E-T Asme 129 (4):677-689. https://doi.org/10.1115/1.2738131.

18. Hoa C, Demolder B, Alexandre A (2003) Roadmap for developing heat pipes for ALCATEL SPACE's satellites. Appl Therm Eng 23 (9):1099-1108. https://doi.org/10.1016/S1359-4311(03)00039-5.

19. Ding $S$, Jin S (2016) Microbulging extrusion of aluminum alloy to fabricate micro/meso features for heat pipes. Int J Adv Manuf Technol 86(9-12):2975-2987. https://doi.org/10.1007/s00170-016-8384$z$.

20. Qamar SZ, Chekotu JC, Qamar SB (2019) Effect of shape complexity on ram pressure and metal flow in aluminum extrusion. Jom-Us 71(12):4378-4392. https://doi.org/10.1007/s11837-019-03748-6.

21. Chen L, Zhao G, Yu J, Zhang W, Wu T (2014) Analysis and porthole die design for a multi-hole extrusion process of a hollow, thin-walled aluminum profile. Int J Adv Manuf Tech 74 (1-4):383-392. https://doi.org/10.1007/s00170-014-6003-4.

22. Yang Z, Xu C, Nakata T, Kamado S (2021) Effect of extrusion ratio and temperature on microstructures and tensile properties of extruded Mg-Gd-Y-Mn-Sc alloy. Mat Sci Eng a-Struct 800:140330. https://doi.org/10.1016/j.msea.2020.140330.

23. Yu Z, Xu C, Meng J, Liu K, Fu J, Kamado S (2019) Effects of extrusion ratio and temperature on the mechanical properties and microstructure of as-extruded Mg-Gd-Y-(Nd/Zn)-Zr alloys. Mat Sci Eng aStruct 762:138080. https://doi.org/10.1016/j.msea.2019.138080.

24. Karabay S, Zeren M, Yilmaz M (2003) Investigation extrusion ratio effect on mechanical behaviour of extruded alloy AA-6063. J Mater Process Technol 135 (1):101-108. https://doi.org/10.1016/S09240136(02)01110-X

25. Demirci HI, Evlen H (2012) Effect of extrusion ratio on the wear behaviour of Al-Si and Al-Mg alloys. J Alloy Compd 510 (1):26-32. https://doi.org/10.1016/j.jallcom.2011.08.074.

26. Wu Y, Zhang X, Deng Y, Tang C, Zhong Y (2014) Effect of secondary extrusion on the microstructure and mechanical properties of a Mg-RE alloy. Mat Sci Eng a-Struct 616:148-154. https://doi.org/10.1016/j.msea.2014.08.022

27. Li X, Qi W, Zheng K, Zhou N (2015) Enhanced strength and ductility of Mg-Gd-Y-Zr alloys by secondary extrusion. J Magnes Alloy 1(1):54-63. https://doi.org/10.1016/j.jma.2013.02.006.

28. Yong T, Ping C, Xiaowu W (2010) Experimental investigation into the performance of heat pipe with micro grooves fabricated by Extrusion-ploughing process. Energy Convers Manag 51(10):18491854. https://doi.org/10.1016/j.enconman.2010.01.001.

29. Reggiani B, Donati $L$ (2019) Prediction of liquid nitrogen die cooling effect on the extrusion process parameters by means of FE simulations and experimental validation. J Manuf Process 41:231-241. https://doi.org/10.1016/j.jmapro.2019.04.002.

30. Zajac S, Hutchinson B, Johansson A, Gullman LO (1994) Microstructure Control and Extrudability of Al-Mg-Si Alloys Microalloyed with Manganese. Mater Sci Tech-Lond 10 (4):323-333. https://doi.org/10.1179/mst.1994.10.4.323. 
31. Van Geertruyden WH, Misiolek WZ, Wang PT (2005) Surface grain structure development during indirect extrusion of 6xxx aluminum alloys. J Mater Sci 40 (14):3861-3863.

https://doi.org/10.1007/s10853-005-2545-z

32. S. Gorelik (1981) Recrystallization in metals and alloys. Mir, Moscow.

33. Chen GJ, Chen L, Zhao GQ, Zhang CS, Cui WC (2017) Microstructure analysis of an Al-Zn-Mg alloy during porthole die extrusion based on modeling of constitutive equation and dynamic recrystallization. J Alloy Compd 710:80-91. https://doi.org/10.1016/j.jallcom.2017.03.240.

34. Donati L, Tomesani L (2004) The prediction of seam welds quality in aluminum extrusion. J Mater Process Tech 153:366-373. https://doi.org/10.1016/j.jmatprotec.2004.04.215.

35. Zhang CS, Wang CX, Zhang QY, Zhao GQ, Chen L (2019) Influence of extrusion parameters on microstructure, texture, and second-phase particles in an Al-Mg-Si alloy. J Mater Process Technol 270:323-34. https://doi.org/10.1016/j.jmatprotec.2019.03.014.

36. Kaneko S, Murakami K, Sakai T (2009) Effect of the extrusion conditions on microstructure evolution of the extruded Al-Mg-Si-Cu alloy rods. Mat Sci Eng a-Struct 500 (1-2):8-15. https://doi.org/10.1016/j.msea.2008.09.057.

37. Shen FH, Zhou ZR, Li WF, Sun ZZ, Tian J, Xie CX, Guo JW, Liao ZL, Yi DQ, Zhang JY, Wang HS, Jiang $B$ (2019) Micro-mechanism of texture evolution during isochronal annealing of as-annealed hot rolled Al-Cu-Mg sheet. Mater Design 165: 107575. https://doi.org/10.1016/j.matdes.2018.107575.

\section{Figures}

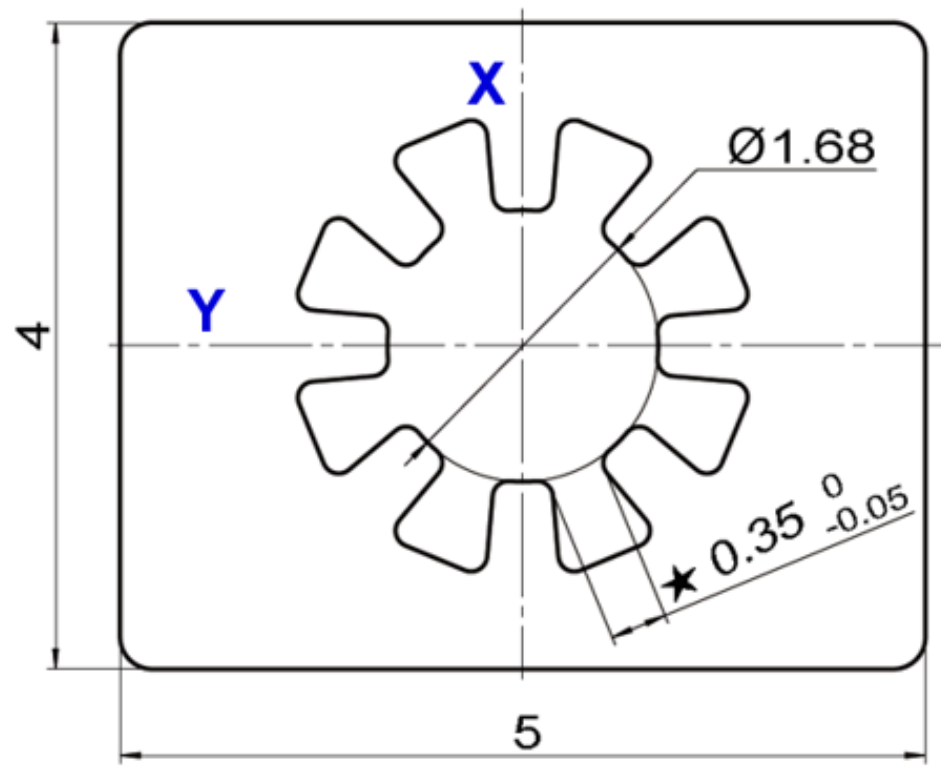

(a)

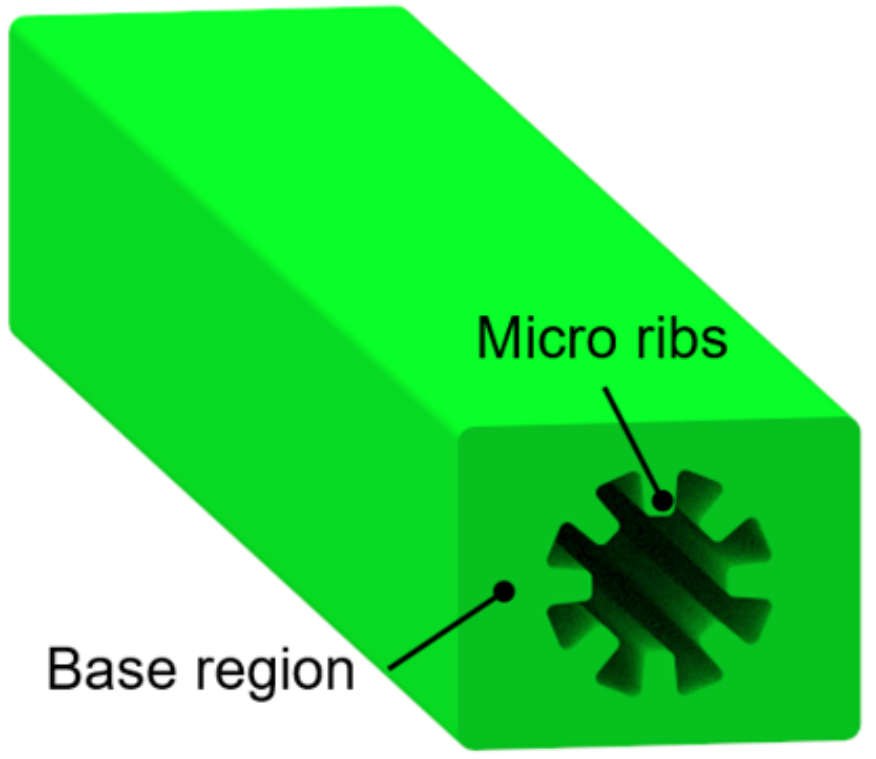

(b)

\section{Figure 1}


MHP profile: (a) cross-sectional dimensions, (b) three-dimensional shape.

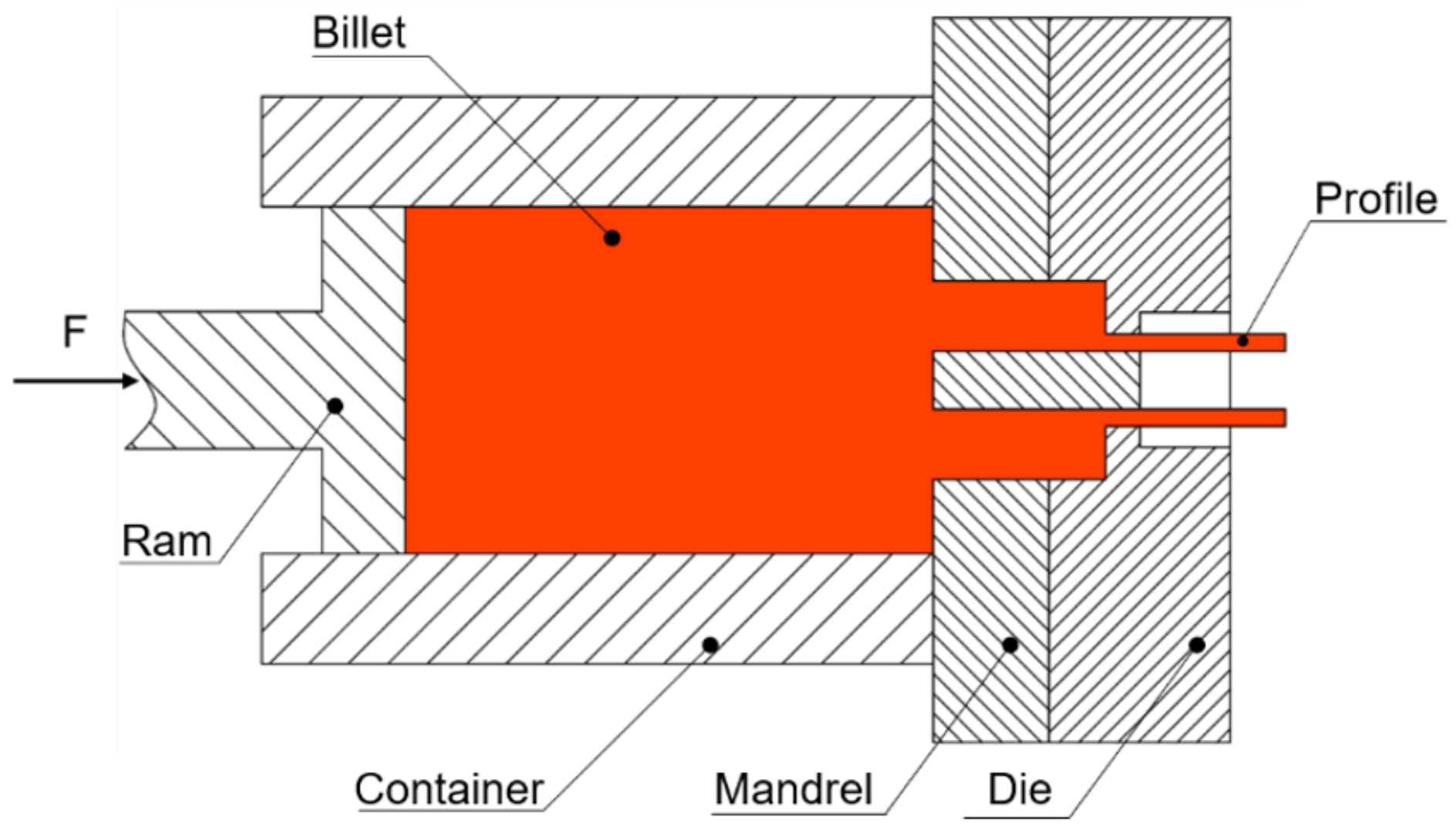

Figure 2

Schematic of porthole die extrusion for hollow profiles. 


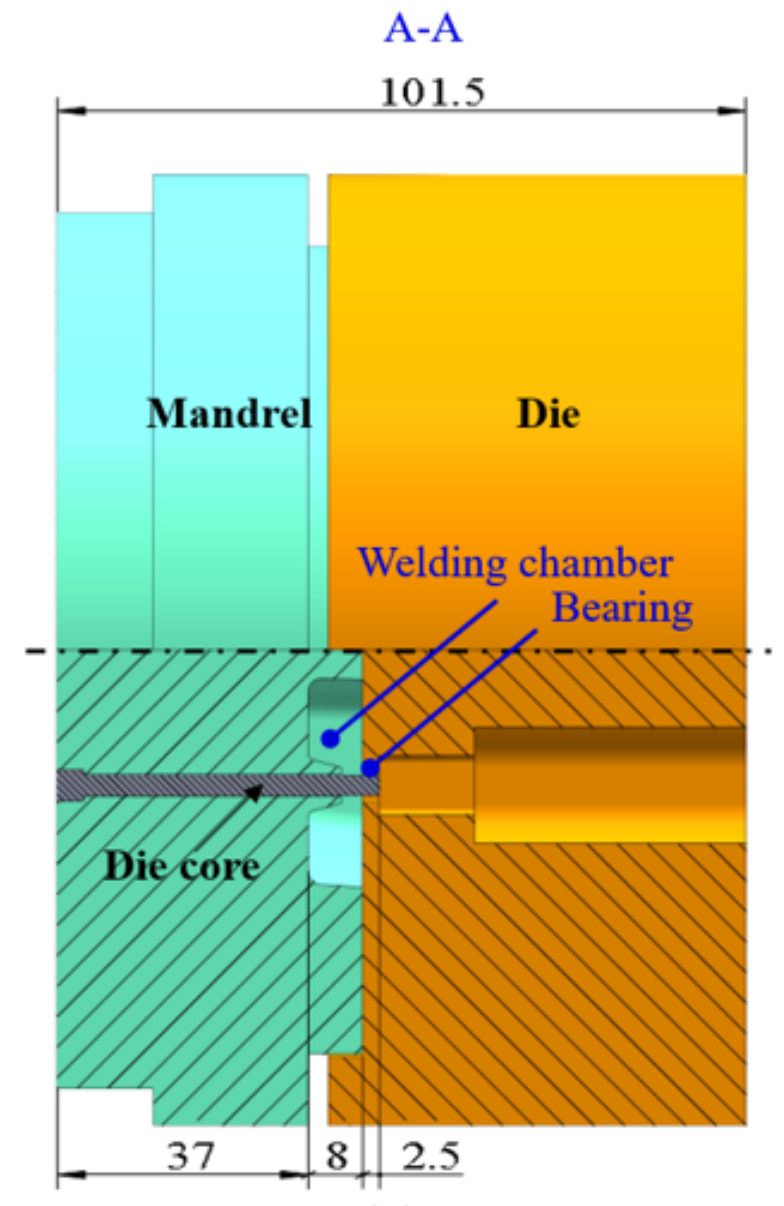

(a)

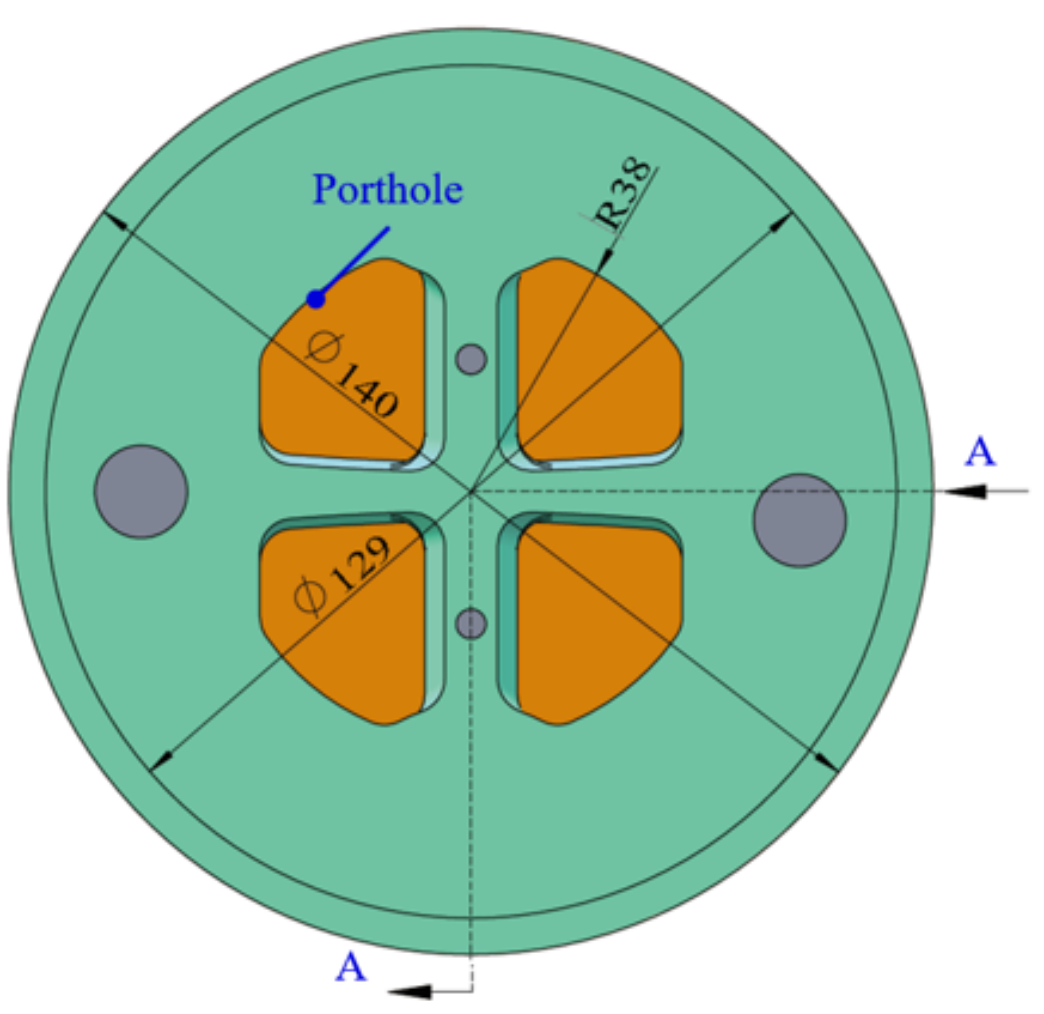

(b)

\section{Figure 3}

Key geometric dimensions of the porthole die for MHP profile: (a) half-cutaway view of the front view, (b) top view. 


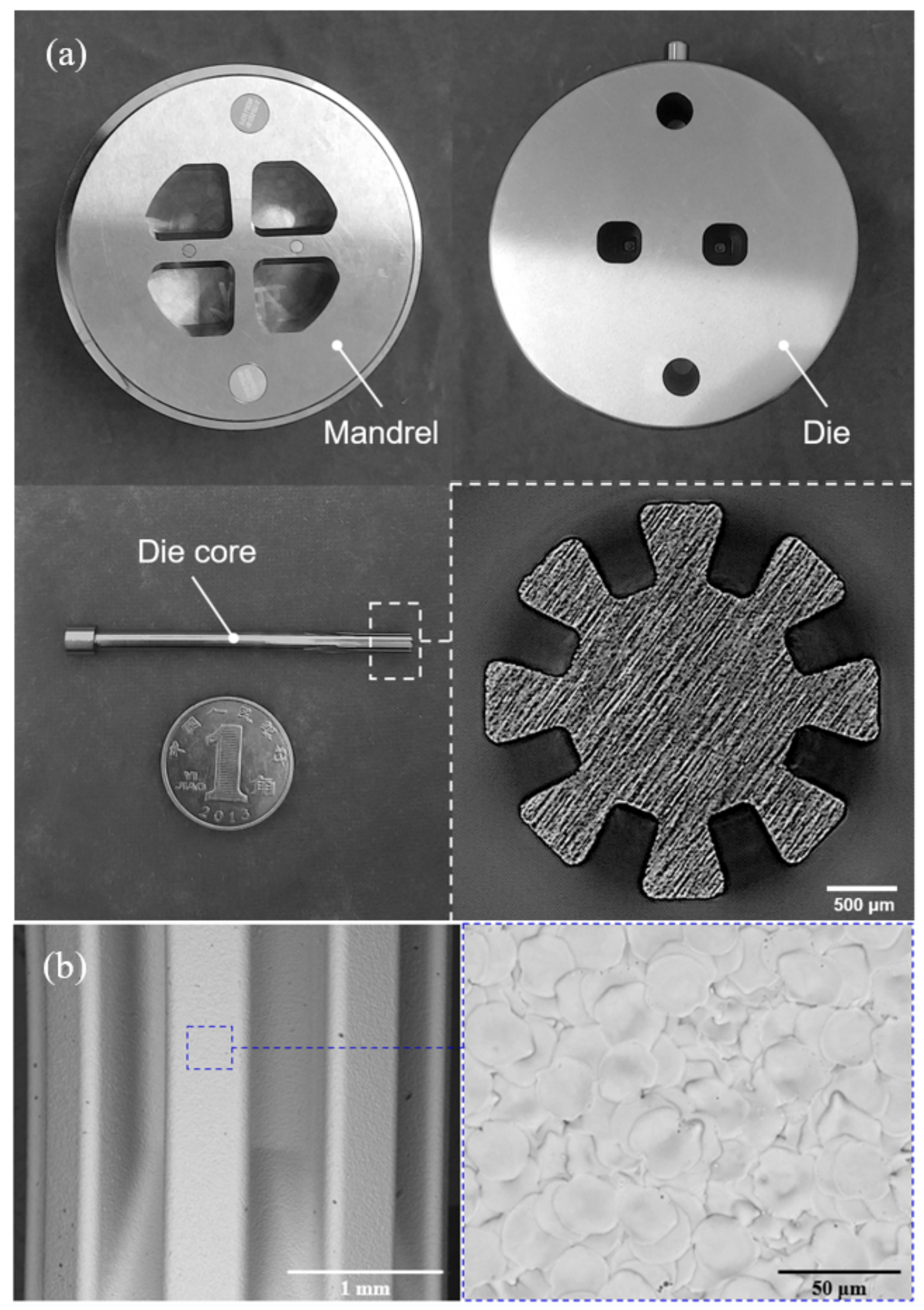

Figure 4

The porthole die: (a) appearance (b) SEM images of the die core. 


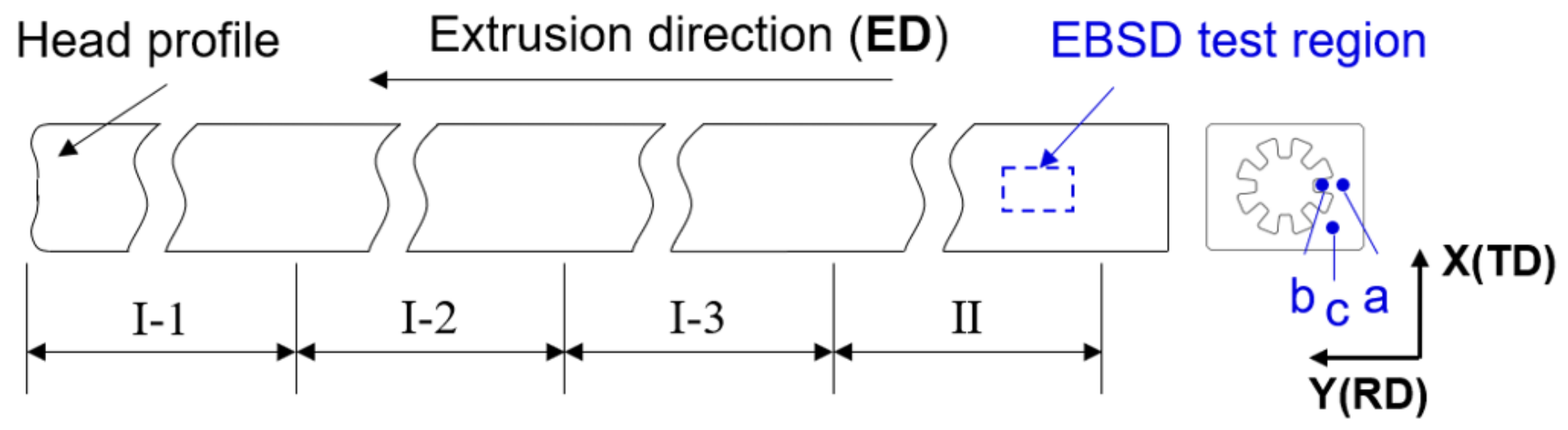

Figure 5

Test sampling locations on the MHP profile.

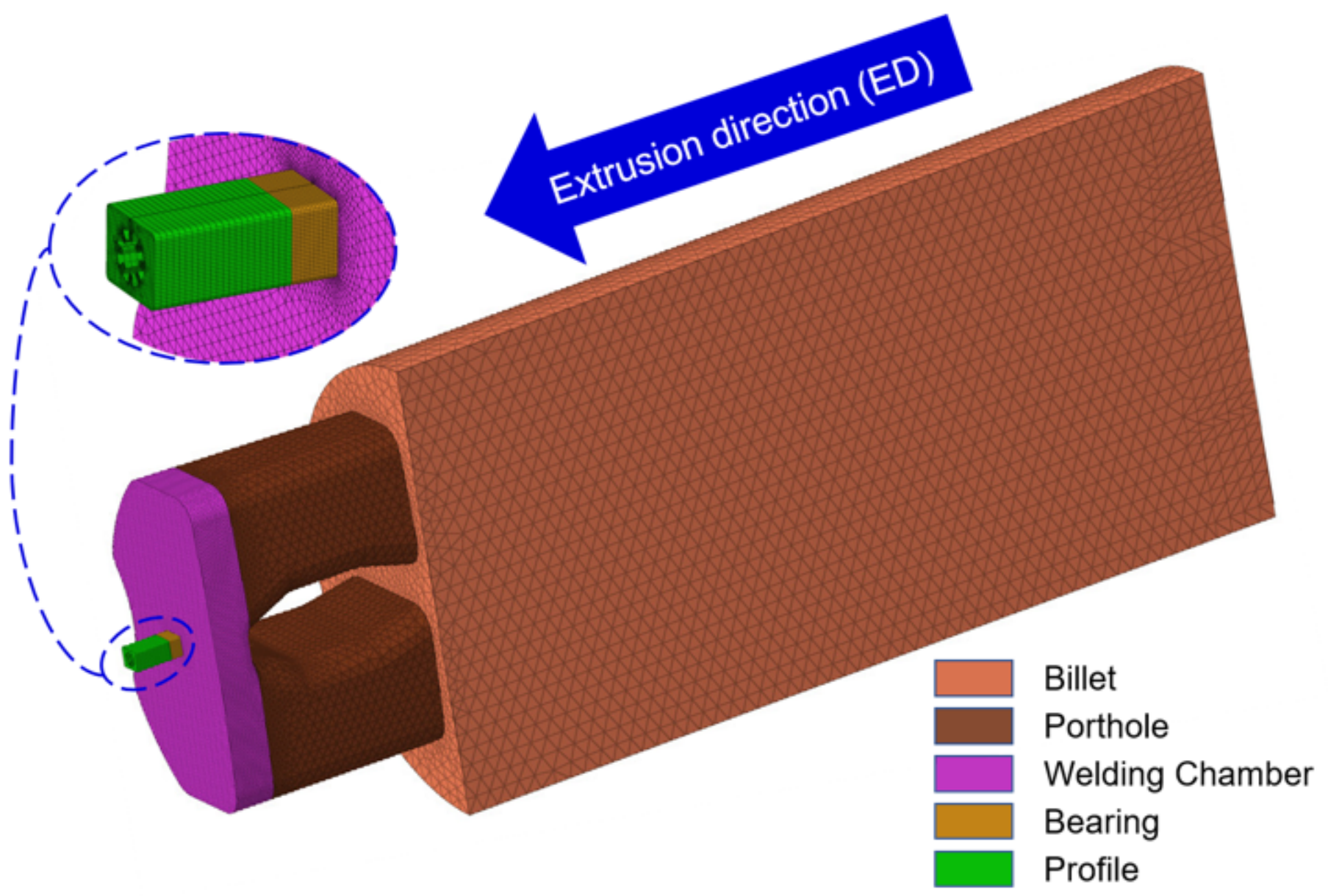

Figure 6

$1 / 2$ axisymmetric three-dimensional elements model of material flow domain during the porthole die extrusion. 


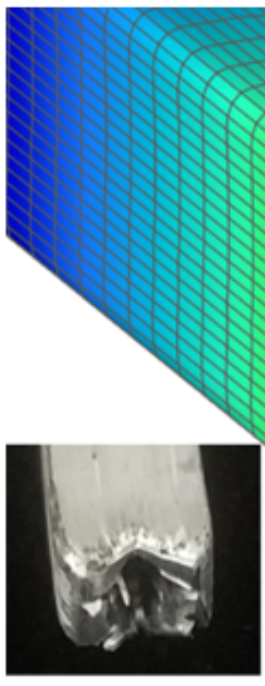

Contour Plot

Temperature

(deg C)(Scalar value)

514.4
-513.6
-512.8
-512.0
-511.2
-510.4
-509.6
-508.9
-508.1
507.3

[1] No Res

$\operatorname{Max}=514.4$

Min $=507.3$

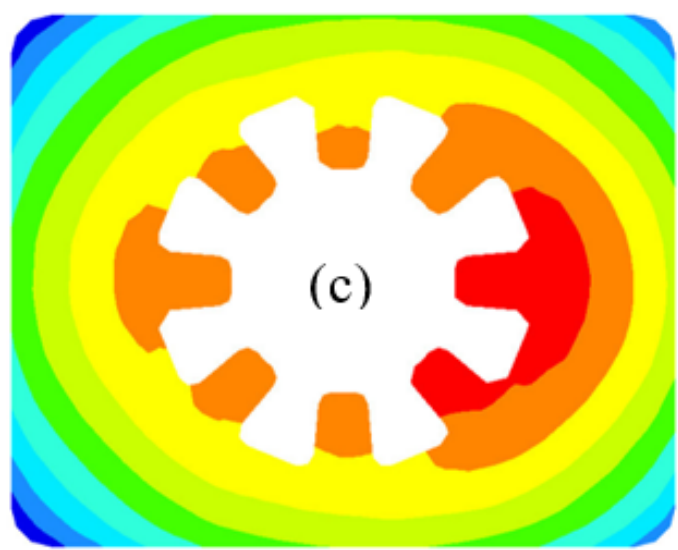

(a)

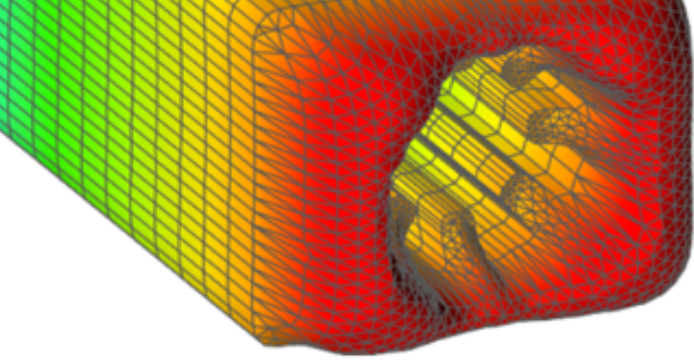

Contour Plot

Temperature

(deg C)(Scalar value)

- $\begin{array}{r}538.6 \\ -537.3\end{array}$

- 536.0

- 534.7

- 533.4

- 532.1

- 530.8

- 529.5

528.2

526.9

(1) No Rest

Max $=538.6$

$\operatorname{Min}=526.9$

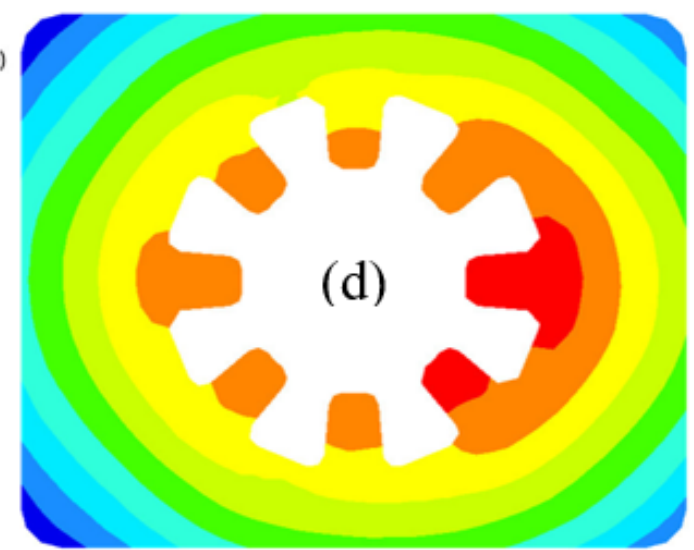

Contour Plot Strain(Scalar value)

- $\begin{array}{r}51.2 \\ 46.0 \\ -\quad 40.9\end{array}$

- 35.7

- 30.6

- 25.4

- 20.3

- 15.1

10.0

48

No Result

$\operatorname{Max}=51.2$

$\operatorname{Min}=4.8$

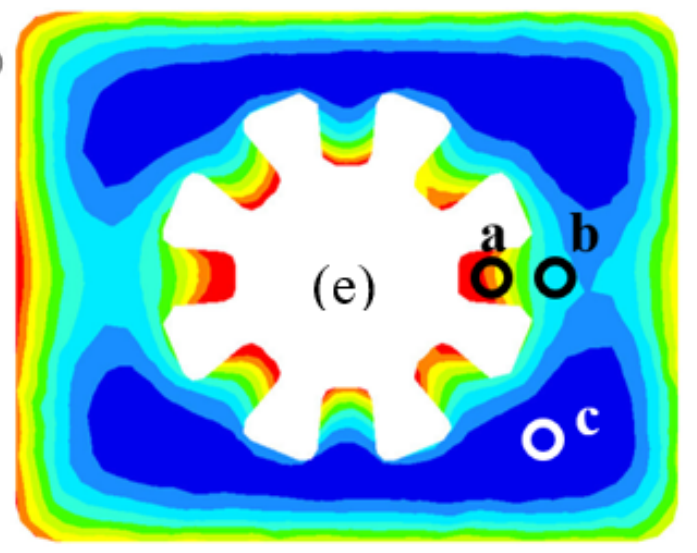

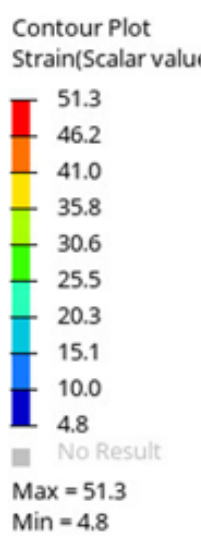

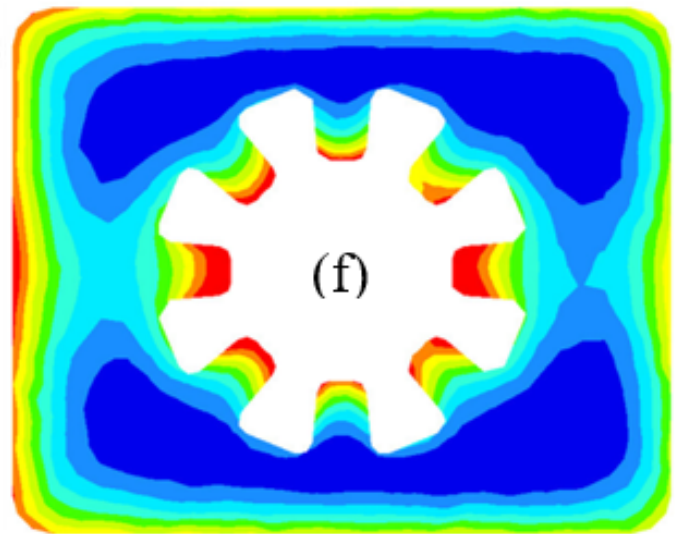

Figure 7

Simulation results of steady extrusion at different ram speeds: (a) the head profile at $0.7 \mathrm{~mm} / \mathrm{s}$, (b) PEV at $0.7 \mathrm{~mm} / \mathrm{s}$, (c) (d) temperature distribution at $0.7 \mathrm{~mm} / \mathrm{s}$ and $1.4 \mathrm{~mm} / \mathrm{s}$ respectively, (e) (f) strain distribution at $0.7 \mathrm{~mm} / \mathrm{s}$ and $1.4 \mathrm{~mm} / \mathrm{s}$ respectively. 


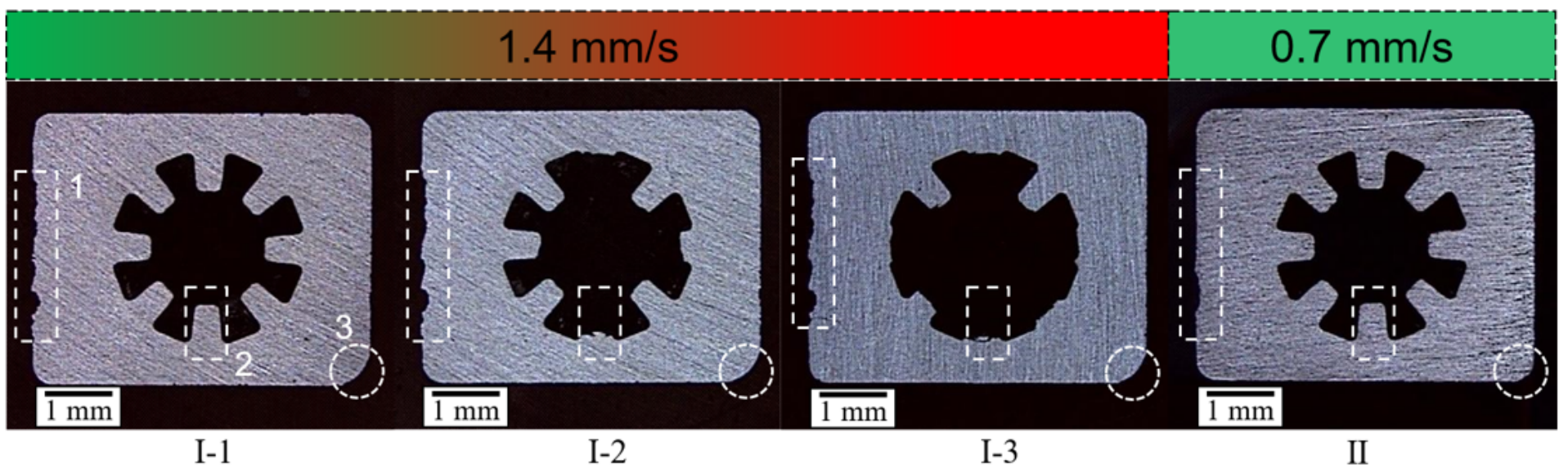

Figure 8

Cross-section images of the MHP profile at different ram speeds.

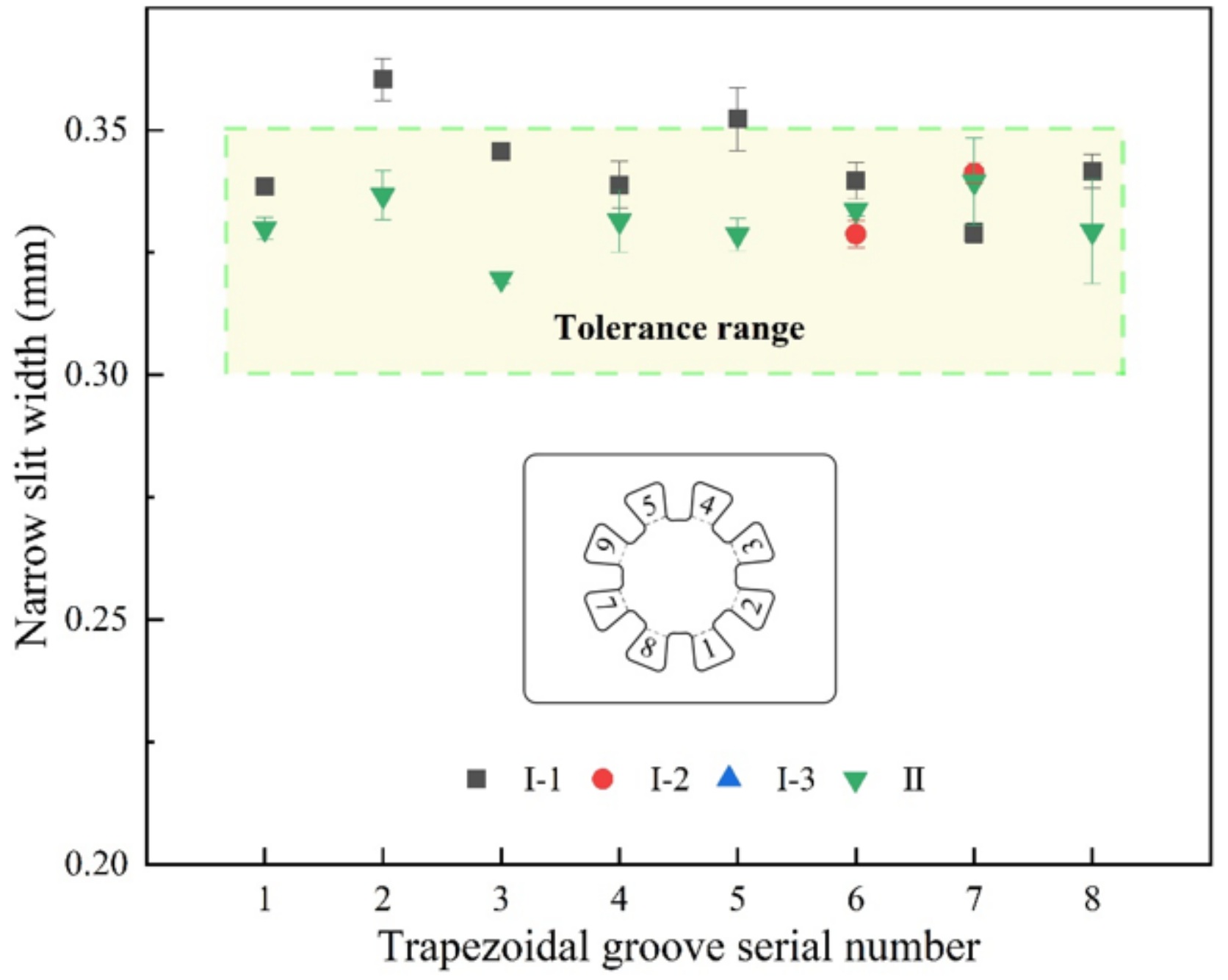

Figure 9

Geometric dimension of the narrow slit width in micro trapezoidal grooves. 
(a)
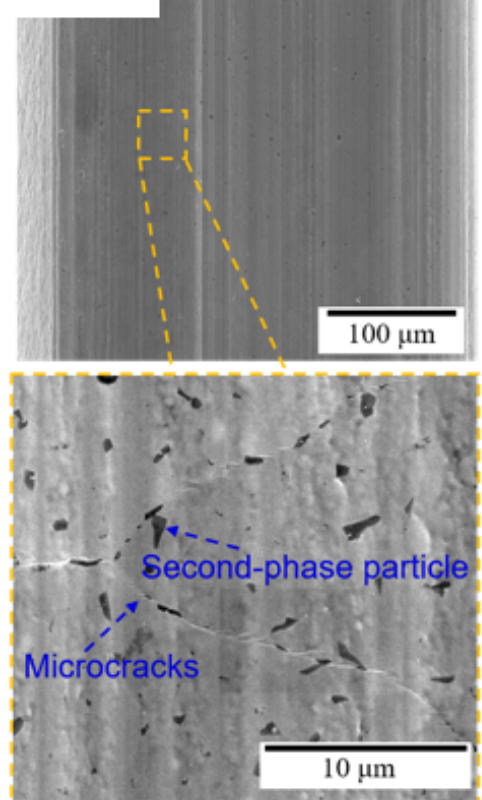

(b)
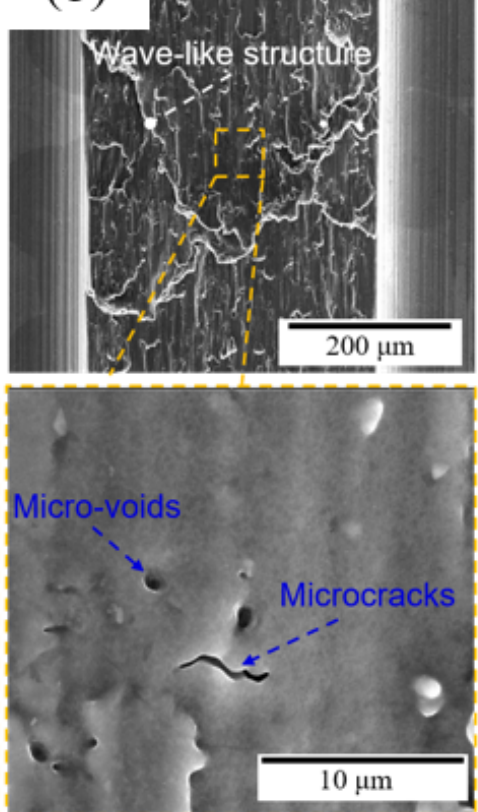

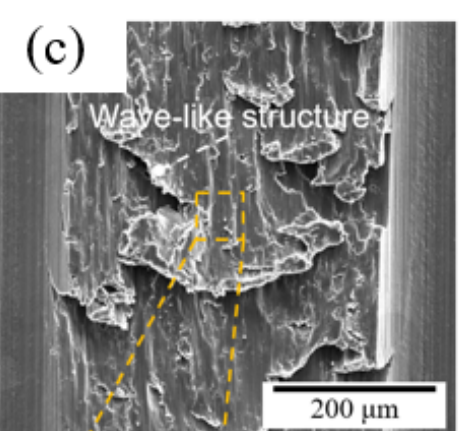

(d)

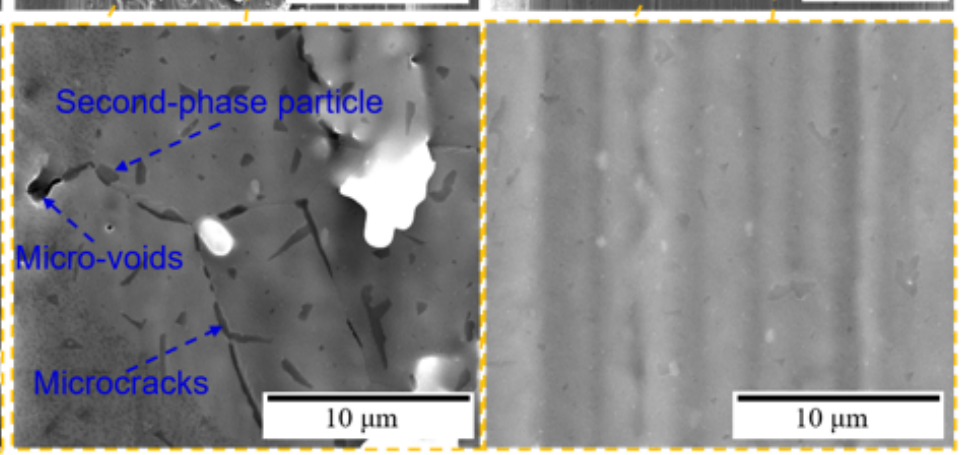

\section{Figure 10}

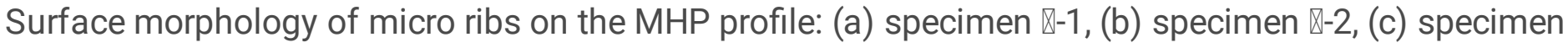

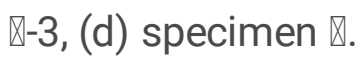




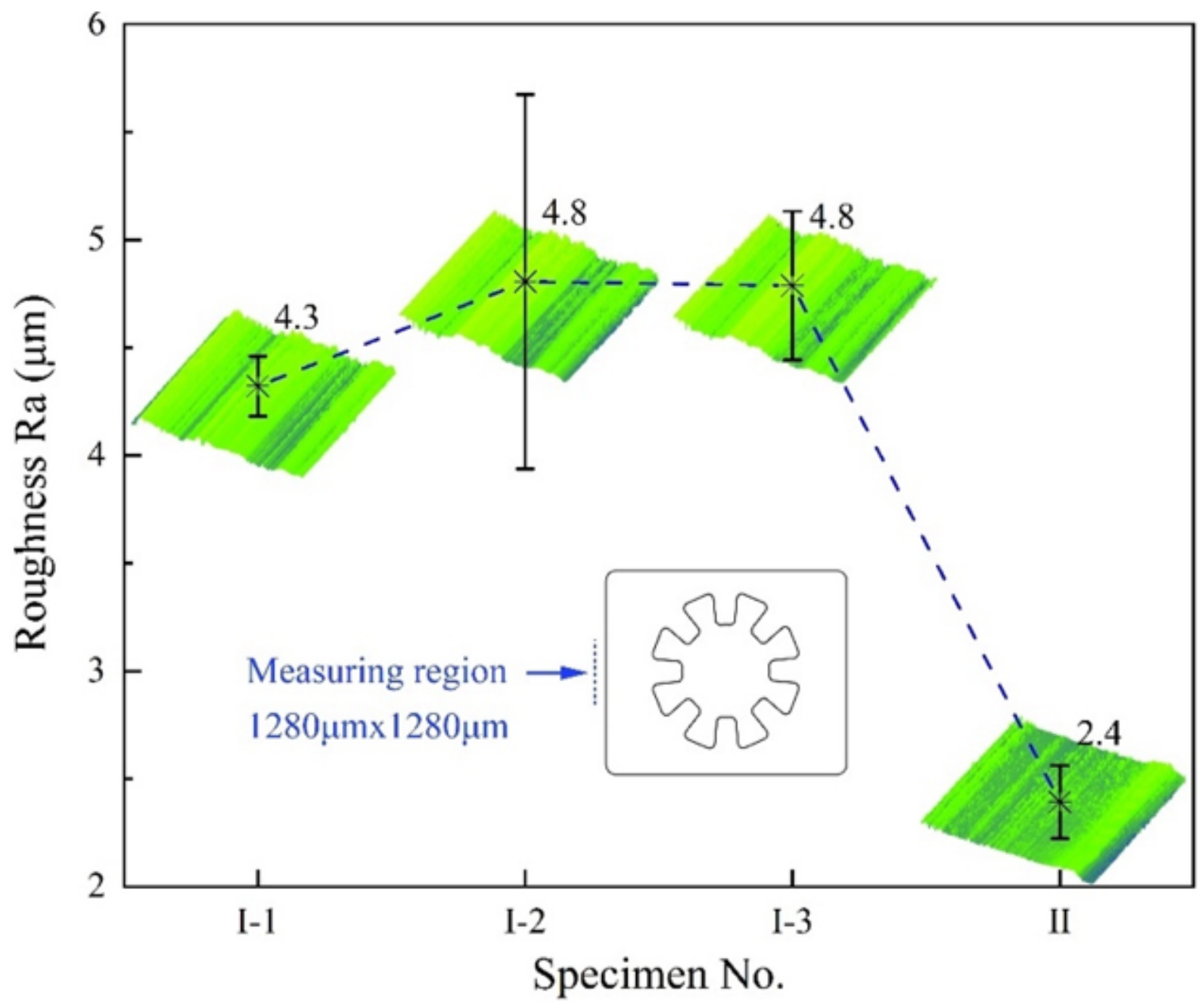

Figure 11

Roughness value of external surfaces of the MHP profile. 


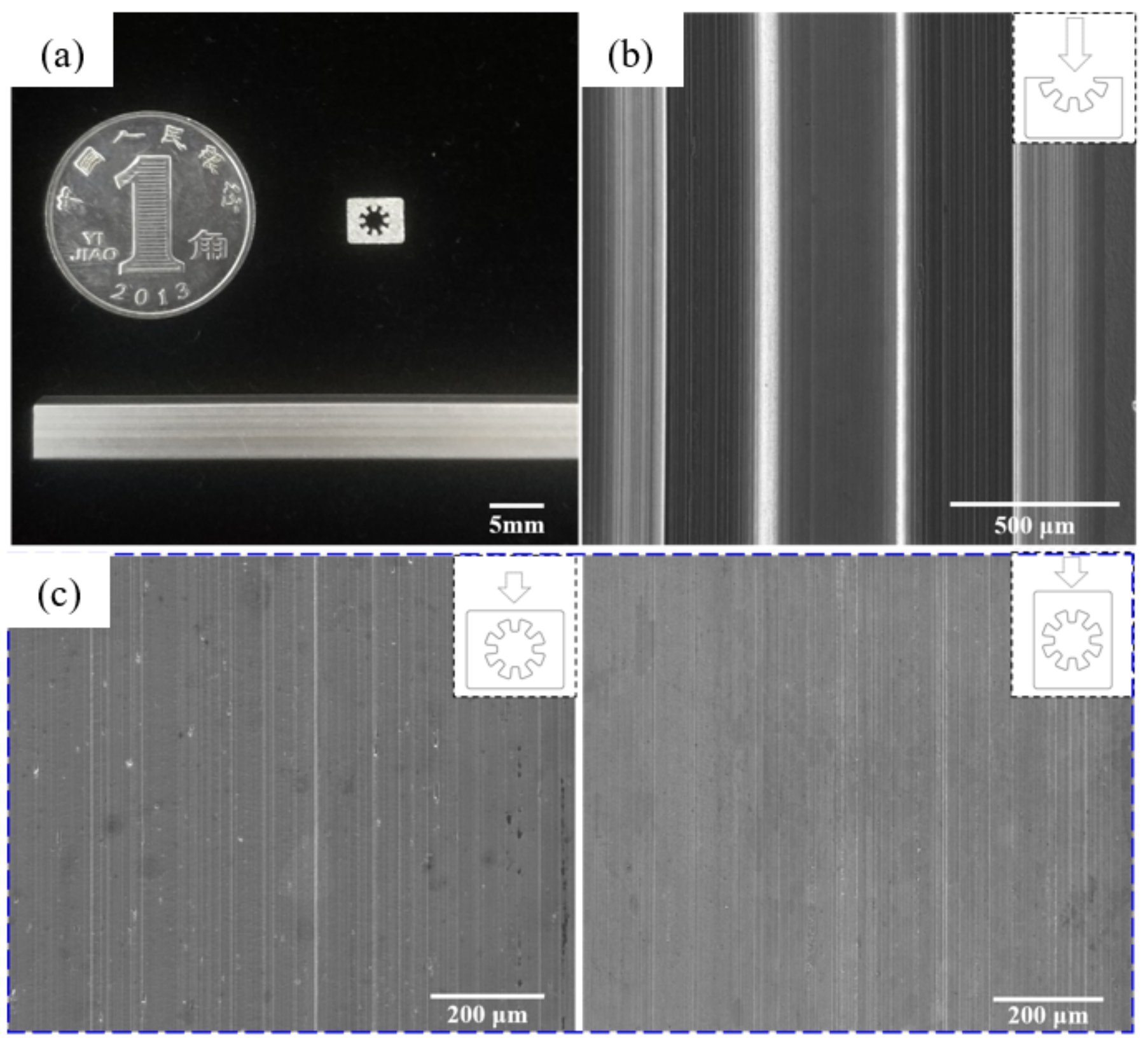

Figure 12

The manufactured MHP profile: (a) macrophoto, (b) SEM images of micro grooves, (c) SEM images of external surfaces. 

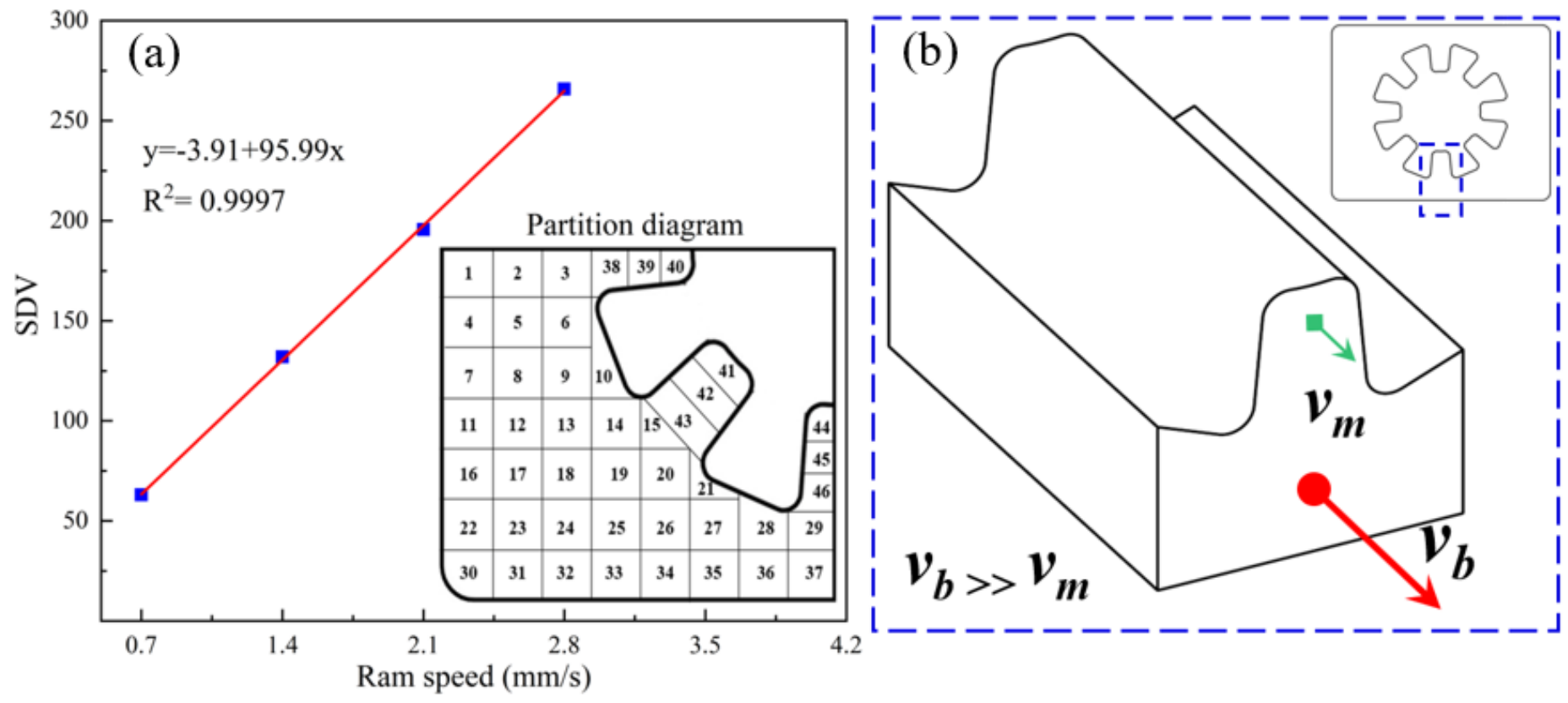

Figure 13

The influence of ram speed on material flow: (a) Linear fit results of SDV value with ram speeds, (b) the characteristic of the PEV for single micro rib. 

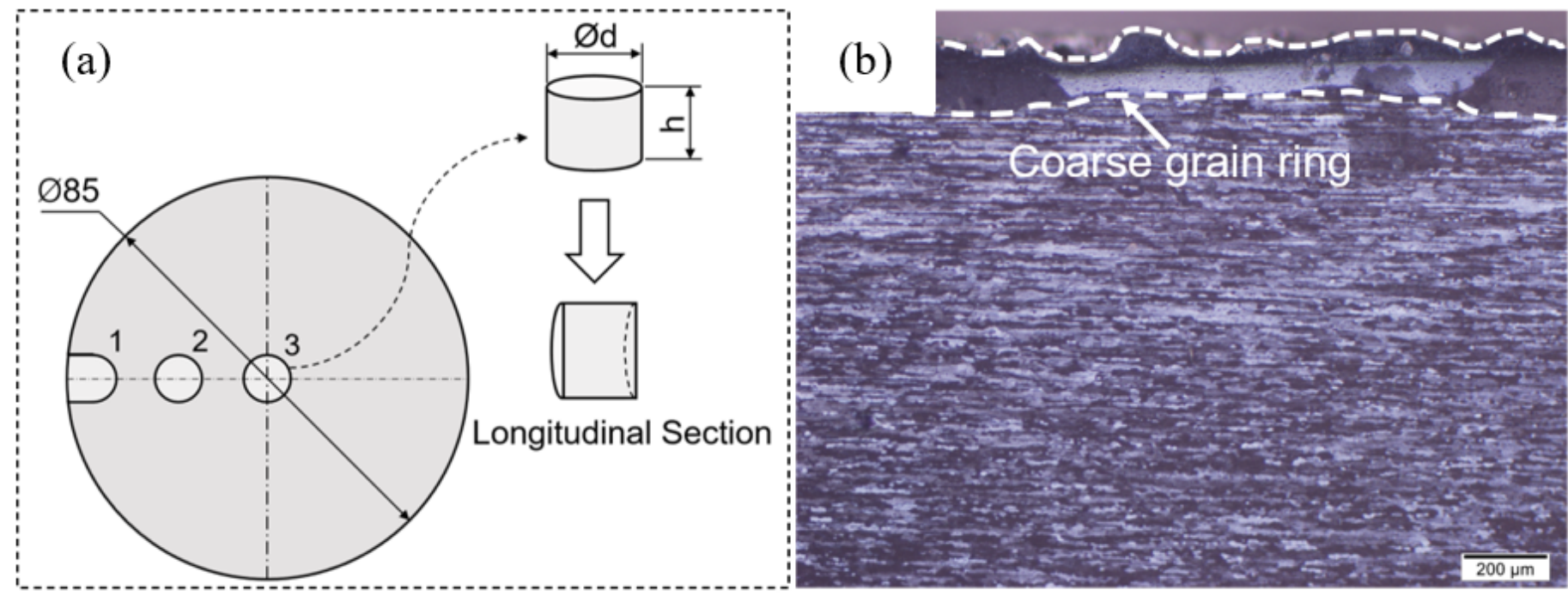

(c)
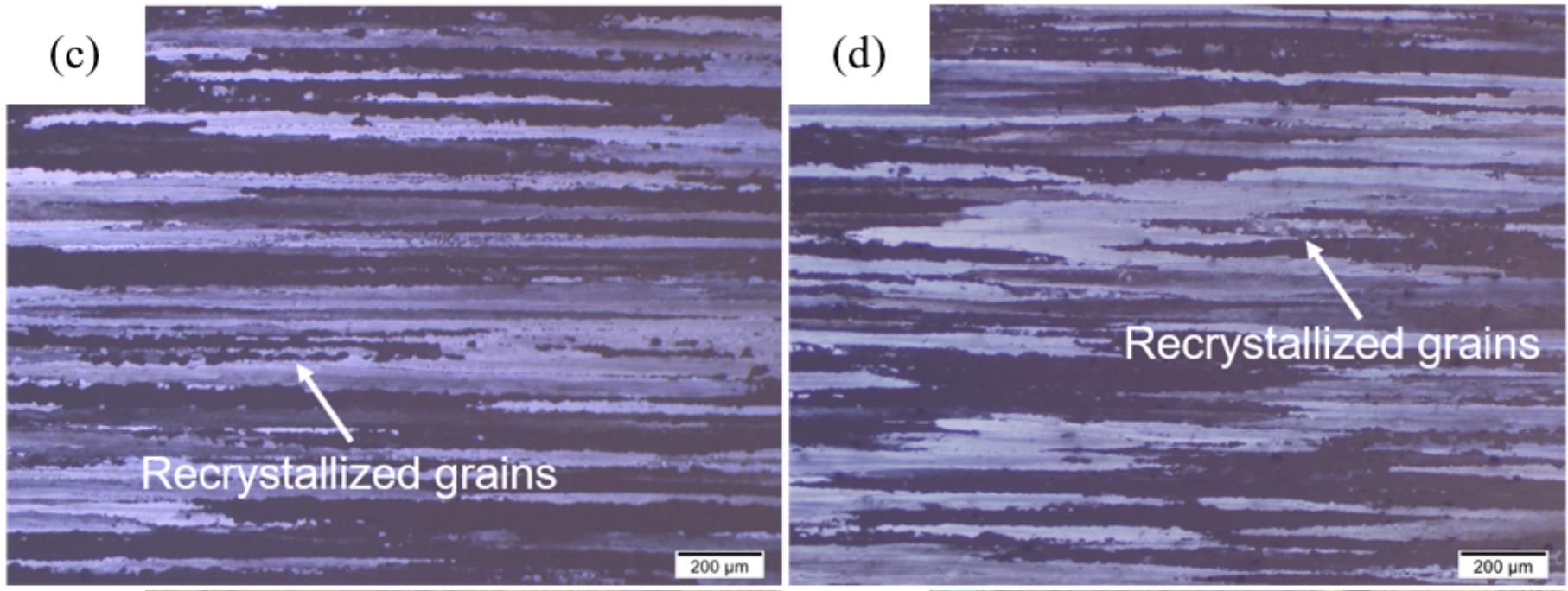

\section{(e)}
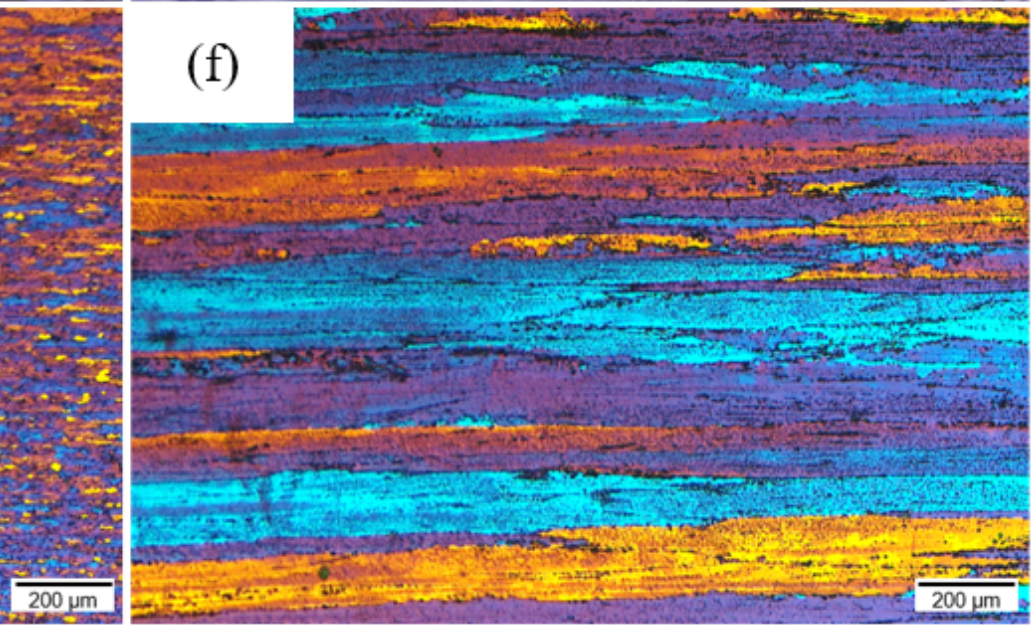

\section{Figure 14}

Metallographic structure of the as-extruded billets: (a) sampling position, (b) zone 1, (c) zone 2, (d) zone 3 , (e) zone 1 after preheating, (f) zone 3 after preheating. 


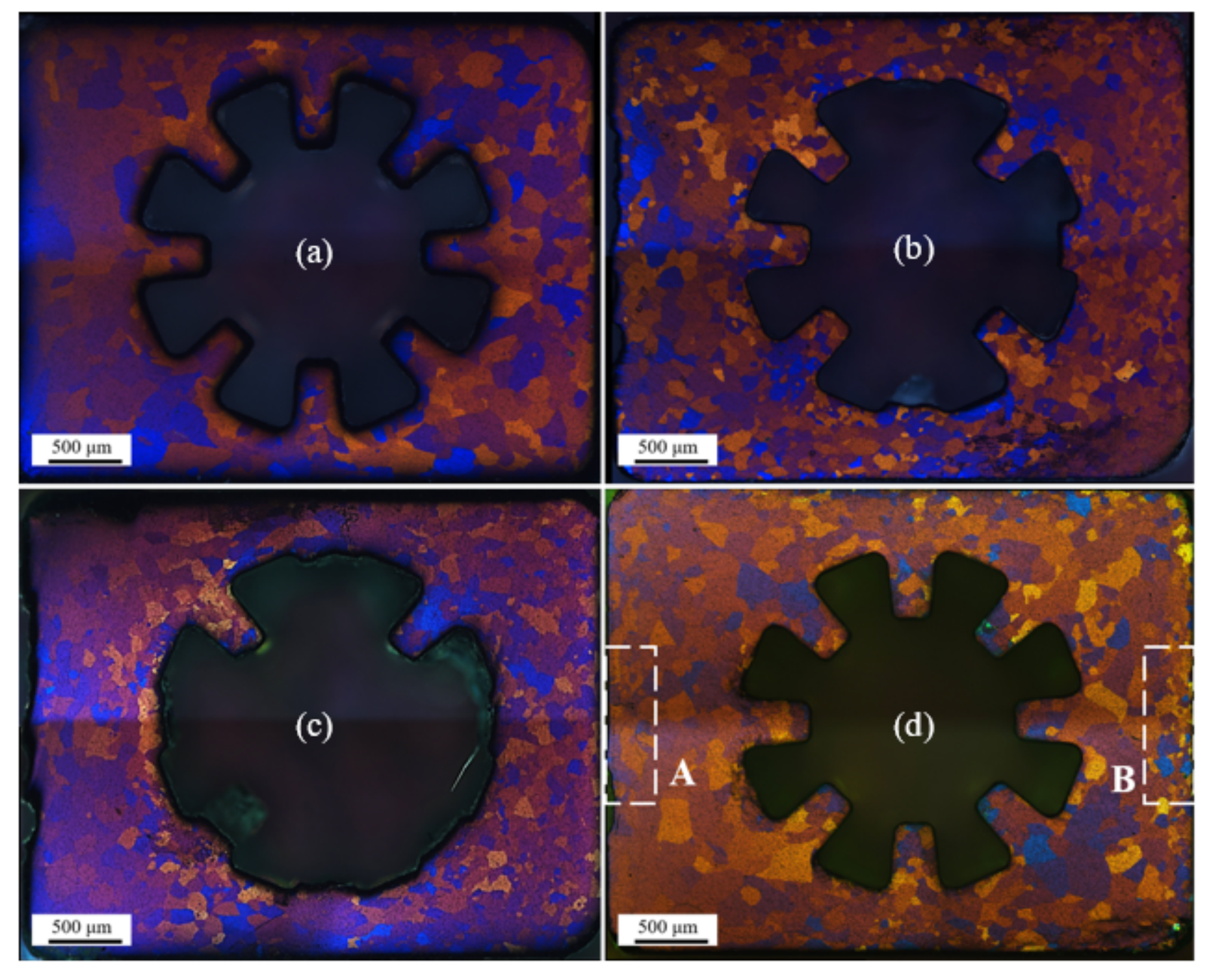

\section{Figure 15}

Metallographic microstructure of the cross-section of the MHP profile: (a) specimen I-1, (b) specimen I-2, (c) specimen $\mathrm{I}-3$, (d) specimen $\mathbb{Q}$. 


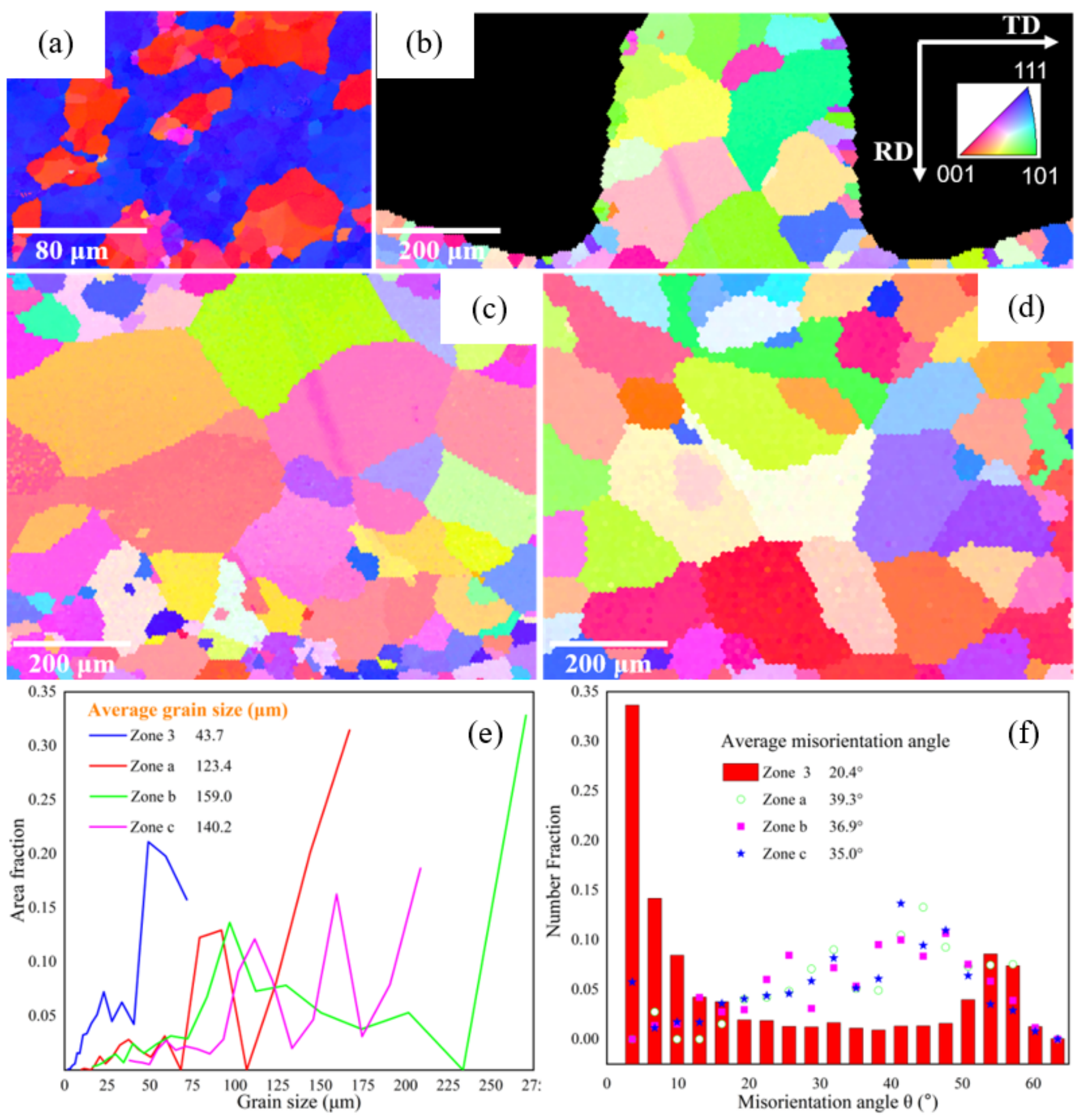

Figure 16

EBSD results: (a) zone 3 at the extruded-billets, (b) zone a, (c) zone b, (d) zone c, (e) grain size, (f) misorientation angle. 


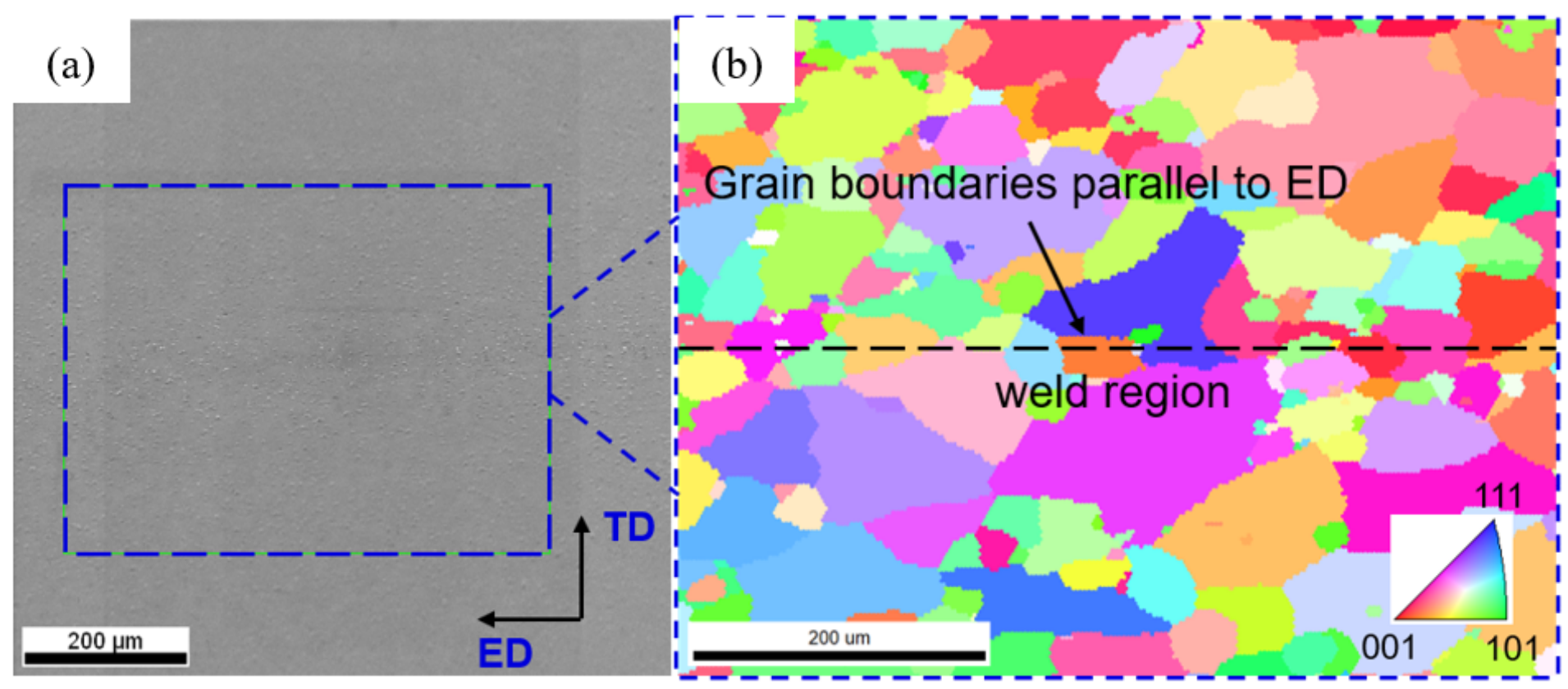

Figure 17

The region near longitudinal welds of the MHP profile: (a) SEM images, (b) inverse pole figure. 

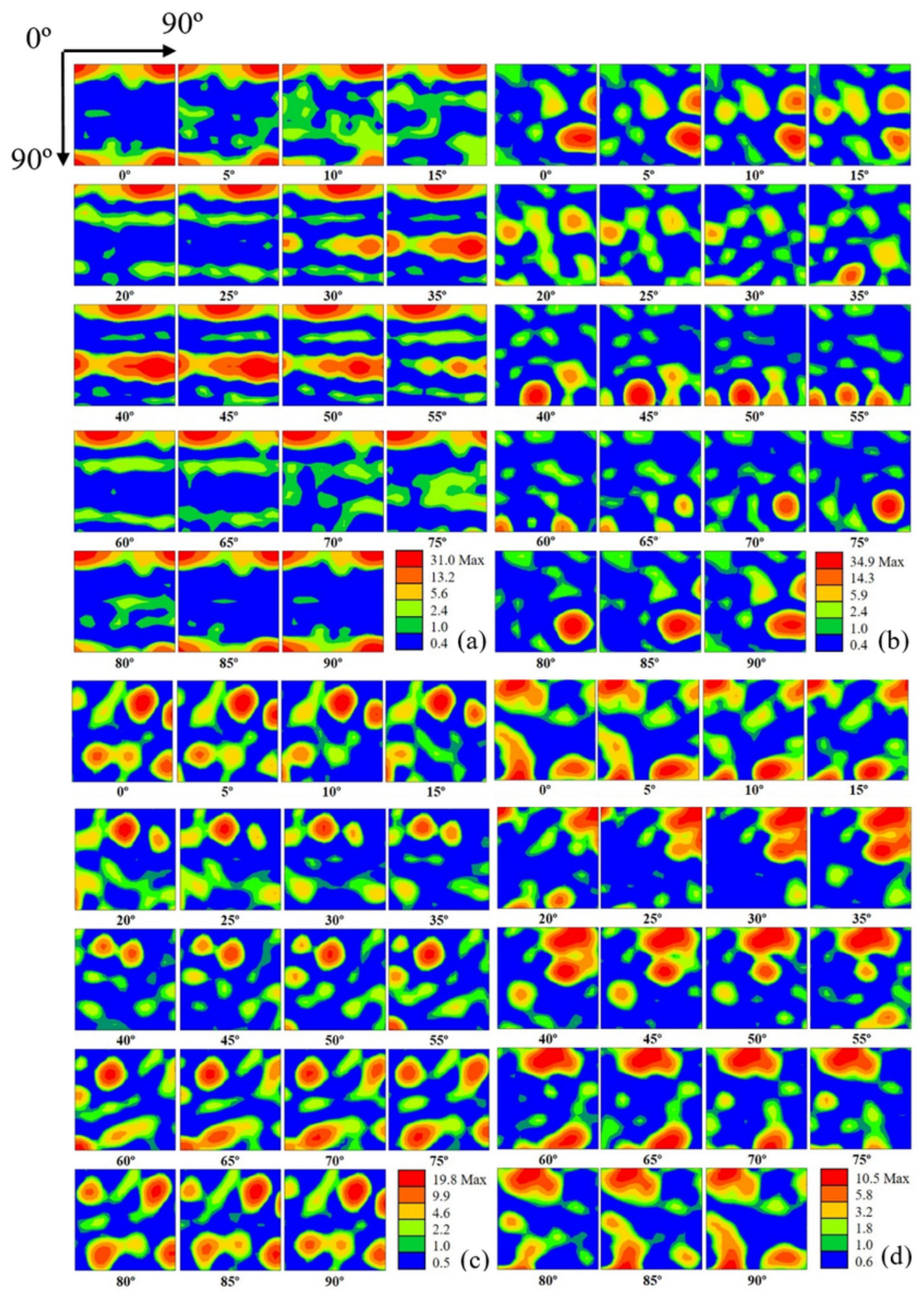

Figure 18

ODF sections (constant angle $\varphi 2$ ): (a) zone 3 at the as-extruded billets, (b) zone a, (c) zone b, (d) zone c. 


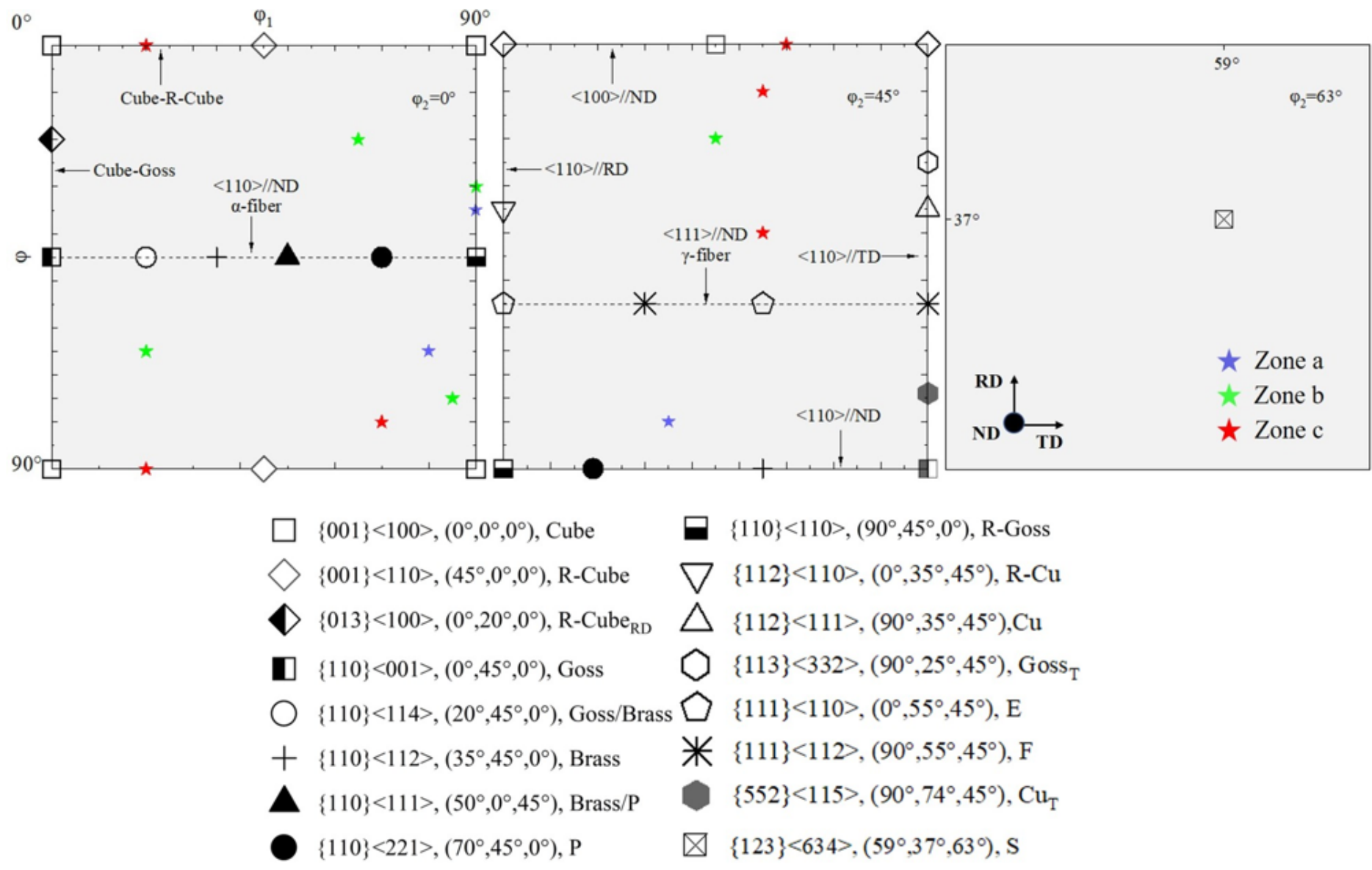

Figure 19

ODF sections $\left(\varphi 2=0^{\circ}, 45^{\circ}, 63^{\circ}\right)$ of texture components in 6063 aluminum alloy after micro-extrusion with as-extruded billets, as well as FCC alloy [37]. 